\title{
Furan formation pathways exploration in low temperature oxidation of 1,3- butadiene, trans-2-butene, and cis-2-butene
}

Bingjie Chen a , Peng Liu ${ }^{\text {b,* }}$, Zepeng Li ${ }^{\text {a, Nils Hansen }}{ }^{\text {c }}$, William L. Roberts ${ }^{\text {b }}$, Heinz Pitsch ${ }^{\text {a }}$

a Institute for Combustion Technology, RWTH Aachen University, Templergraben 64, Aachen 52056, Germany

b King Abdullah University of Science and Technology (KAUST), Clean Combustion Research Center, Thuwal, 23955-6900,

Saudi Arabia

c Combustion Research Facility, Sandia National Laboratory, Livermore, CA, 94551, USA

\section{Abstracts:}

Furan is one of the smallest organic compounds with heterocycle ring. With this particular molecular structure, furan is considered as a highly toxic and carcinogenic combustion pollutant, and furan may contribute to the formation of oxygenated soot. In this work, furan formation pathways from 1,3-butadiene, trans-2-butene and cis-2-butene were comprehensively explored. The potential energy surfaces, reaction rate coefficients, and thermodynamics were calculated by quantum chemistry using high level of theories including the CCSD (T) and G3 methods. The proposed reaction pathways were then implemented into the AramcoMech 3.0 model uniformly or independently to examine the model performance with the experimental data. The oxidation experiments of 1,3-butadiene, trans-2-butene and cis-2-butene were performed in a jet stirred reactor (JSR) in the low temperature regime (500-830 K). The JSR is coupled with time-of-flight molecular beam mass spectrometry (ToF-MBMS) using synchrotron radiation as photon ionization source for species identification and quantification. Compared with experiments, both updated models (the independent and uniform model) showed better prediction of furan than the

\footnotetext{
* Corresponding author E-mail: peng.liu.1@kaust.edu.sa
} 
base AramcoMech 3.0 model, which highlighted the contribution of the proposed pathways. Reaction pathway analyses reveal that in the proposed reaction pathway, both reactions $\mathrm{C}_{4} \mathrm{H}_{6}+$ $\mathrm{OH} \rightleftharpoons \mathrm{S} 1-4\left(\mathrm{H}_{2} \mathrm{C}=\mathrm{CH}-\dot{\mathrm{C}} \mathrm{H}-\mathrm{CH}_{2} \mathrm{OH}\right.$, but-1-en-3-yl-4-ol $)$ and $\mathrm{C}_{4} \mathrm{H}_{6}+\mathrm{HO}_{2} \rightleftharpoons \mathrm{C}_{4} \mathrm{H}_{6} 1-3 \mathrm{OOH} 4$ $\left(\mathrm{H}_{2} \mathrm{C}=\mathrm{CH}-\mathrm{C} \mathrm{H}-\mathrm{CH}_{2} \mathrm{OOH}\right.$, but-1-en-3-yl-4-peroxide) not only contribute to furan formation, but also to fuel consumption. Furthermore, the kinetic uncertainty from activation energy calculated by the CCSD series methods, CBS-ANPO, and G4 methods was evaluated for reaction $\mathrm{C}_{4} \mathrm{H}_{6}+$ $\mathrm{HO}_{2} \rightleftharpoons \mathrm{C}_{4} \mathrm{H}_{6} 1-3 \mathrm{OOH} 4$. Instead of developing a new kinetic model, this work aims at proposing and validating new reaction pathways to advance the understanding of furan formation chemistry in low temperature oxidation, and provide guidance for future model development.

Keyword: furan; reaction pathway; low temperature oxidation; pathway analysis; reaction rate coefficients.

\section{Introduction}

Heterocycles are harmful pollutants that can have detrimental effects on human health and air quality. One of the most common small heterocycles is furan with four carbon atoms and one oxygen atom in the conjugated ring. The furan has low molecular weight of $68 \mathrm{~g} / \mathrm{mol}$, a high volatility and a high hydrophobicity, so it can be inhaled and dissolved in the organic tissues [1]. Many medical studies have identified furan to be highly carcinogenic [2,3]. Some studies on mice

showed that furan had a high risk of hepatocellular adenomas and carcinomas [4], and the World Health Organization listed furan as a carcinogenic substance with high priority [5].

Furan is not only harmful to the human health, but also may have a minor effect on climate change. The high amount of furan released from combustion contributes to the formation of oxygenated polycyclic aromatic hydrocarbons (OPAH) [6]. The OPAH molecules with furanic 
structures, e.g. dibenzofuran, have relatively low Gibbs free energies due to ring conjugation, so they can survive longer at high flame temperatures $[7,8]$. OPAH can be attached to the surface of the soot particles [9-11], hence increasing their hygroscopicity [12]. These hydrophobic soot particles can influence the climate by absorbing large amounts of water vapor before acting as nuclei for cloud condensation [13]. The effect of soot hygroscopicity on cloud condensation and climate change is a large uncertain part in the climate predictions $[14,15]$.

The attention to furan emission is growing with the prevalence of bio-fuels for engines and power plants [16], especially since the furan derivatives are proposed as promising candidates for the next generation bio-fuels with low carbon footprint [17]. Elevated furan formation is also reported for biomass combustion $[18,19]$. In practical engines fueled by gasolines and other hydrocarbons, furan is not a direct major emission pollutant due to short residence time, but it may play a role on the OPAH and oxygenated soot formation. Many previous studies focused on the combustion chemistry of furan and its derivatives [20]. Fundamental studies of furan combustion chemistry include ignition delay time [21], speciation in premixed laminar flames [22, 23], counterflow diffusion flames [24], flow reactors [25, 26], and jet-stirred reactors (JSR) [27]. Although a large amount of work has been reported to study furan combustion, the understanding of furan formation is currently limited. Johansson et al. [6] studied the formation chemistry of OPAH with furanic structures at high temperatures in ethylene premixed and diffusion flames. However, studies in the low temperature regime are scarce, and the understanding of furan formation chemistry at low temperatures $(<850 \mathrm{~K})$ needs to be enhanced.

In the latest $\mathrm{C}_{1}-\mathrm{C}_{4}$ reaction mechanisms $[28,29]$, furan formation is described by $1,3-$ butadiene $+\mathrm{HO}_{2} \gtrless 2,5$-dihydrofuran $+\mathrm{OH}$ and 2,5-dihydrofuran $\rightleftharpoons$ furan $+\mathrm{H}_{2}$ reactions with the estimated kinetic parameters in the high temperature regime [30]. The possible contribution of 1,3- 
butadiene $+\mathrm{OH}$ reaction to furan formation is not well studied in the low temperature regime. It is also not clear whether furan can be directly produced from cis-2-butene and trans-2-butene. Since cis-2-butene and trans-2-butene are important primary intermediates from low temperature oxidation of gasoline and butanols, detailed furan formation pathways starting from 1,3-butadiene, trans-2-butene, and cis-2-butene were explored and proposed with the consideration of $\mathrm{OH}$ and $\mathrm{HO}_{2}$ radicals as initial adduct reactants in this work. The low temperature chemistry of 1-butene, another important intermediate in gasoline and butanol combustion, was studied in our previous work [31], but furan was not detected, so it is not included in this work.

The remaining part of the paper is composed as follows. Section 2 describes the methodology of quantum chemistry, reaction rate coefficient calculations, JSR experiments and kinetic modeling. Section 3 shows the proposed furan formation pathways starting from trans-2-butene, 2-butenyl radical, 1,3-butadiene and cis-2-butene. These pathways with their calculated rate coefficients were implemented into the base AramcoMech 3.0 model [29] independently or uniformly to test the influence of the base model on furan formation. Section 4 first presents the experimental identification of furan, followed by furan concentration comparison between experiments and simulations using different kinetic models. Pathway analyses were performed to highlight the contribution of the reactions $\mathrm{C}_{4} \mathrm{H}_{6}+\mathrm{OH} \rightleftharpoons \mathrm{S} 1-4\left(\mathrm{H}_{2} \mathrm{C}=\mathrm{CH}-\dot{\mathrm{C}} \mathrm{H}-\mathrm{CH}_{2} \mathrm{OH}\right.$, but-1-en-3yl-4-ol) and $\mathrm{C}_{4} \mathrm{H}_{6}+\mathrm{HO}_{2} \rightleftharpoons \mathrm{C}_{4} \mathrm{H}_{6} 1-3 \mathrm{OOH} 4\left(\mathrm{H}_{2} \mathrm{C}=\mathrm{CH}-\dot{\mathrm{C}} \mathrm{H}-\mathrm{CH}_{2} \mathrm{OOH}\right.$, but-1-en-3-yl-4-peroxide) to furan formation and fuel consumption. The influence of the deviated activation energies of $\mathrm{C}_{4} \mathrm{H}_{6}$ $+\mathrm{HO}_{2} \rightleftharpoons \mathrm{C}_{4} \mathrm{H}_{6} 1-3 \mathrm{OOH} 4$ is revealed. Pressure dependence is examined for the dominant pathway to furan. Section 5 concludes the whole paper.

\section{Methodology}




\subsection{Quantum chemistry and reaction rate calculations}

The local minimum and transition state structures in all proposed reaction pathways were optimized at the DFT/B3LYP/6-311 G+(d,p) level except for 1,3- $\mathrm{C}_{4} \mathrm{H}_{6}+\mathrm{OH}$ barrier-less addition reaction, where the M06-2X/6-311 G+(d,p) method was used to describe the minimum energy pathway (MEP). The frequencies used in reaction rate calculations were obtained using the same method with a correction factor of 0.967 for the DFT/B3LYP/6-311G+(3df,2p) method [32]. To improve the energy accuracy, single-point energies of each structure were further refined using the G3 and CCSD(T)/cc-pvdz methods with geometry optimized at the DFT/B3LYP/6-311/G+(d,p) level. The G3 method was reported to have a mean absolute deviation of $1.07 \mathrm{kcal} / \mathrm{mol}$ from experiment based on numerous comparisons [33], and the mean error of the CCSD(T)/cc-pvdz method was estimated to be $1.9 \mathrm{kcal} / \mathrm{mol}$ [34]. There were a few reactions where the G3 method failed to converge, so the energy barrier from the $\operatorname{CCSD}(\mathrm{T}) / \mathrm{cc}-\mathrm{pvdz}$ method was used in kinetic calculations instead. The contribution to furan formation from most reactions with energy barrier described by $\operatorname{CCSD}(\mathrm{T}) / \mathrm{cc}-\mathrm{pvdz}$ method was tested to be negligible in the pathway analysis. Therefore, the accuracy of energy barrier is not an issue to affect the corresponding modelling conclusion. By comparison, the energy barriers evaluated by the G3 and CCSD(T)/cc-pvdz methods match well, and the deviation is within $1.5 \mathrm{kcal} / \mathrm{mol}$ for most of the reactions. The biggest energy deviation appears for the 1,3- $\mathrm{C}_{4} \mathrm{H}_{6}+\mathrm{HO}_{2} \rightleftharpoons \mathrm{C}_{4} \mathrm{H}_{6} 1-3 \mathrm{OOH} 4\left(\mathrm{H}_{2} \mathrm{C}=\mathrm{CH}-\dot{\mathrm{C}} \mathrm{H}-\mathrm{CH}_{2} \mathrm{OOH}\right.$, but1-en-3-yl-4-peroxide) reaction, where the forward reaction energy barrier calculated using the G3 method is lower than that using the CCSD(T)/cc-pvdz method by $5.3 \mathrm{kcal} / \mathrm{mol}$. Because of the importance of this reaction, the energy barrier was further calculated using the CCSD(T)/complete basis set extrapolation (CBS) [35], CBS-ANPO, and G4 methods for uncertainty analyses in model predictions. All transition states were carefully examined by the intrinsic reaction coordinate (IRC) 
calculations to ensure that the transition state connects the reactants and products. All quantum chemistry calculations were performed using Gaussian 09 software package (version D.01) [36].

In this study, most of the reactions are bimolecular reactions. For example, one furan formation pathway starting from 1,3-butadiene mainly consists of 1,3-butadiene $+\mathrm{OH} \rightarrow$ 2,5-dihydrofuran $(\mathrm{P} 1-8)+\mathrm{H}, 1,3$-butadiene $+\mathrm{HO}_{2} \rightarrow$ 2,5-dihydrofuran $+\mathrm{OH}$, and $\mathrm{P} 1-8+\mathrm{H} \rightarrow \mathrm{S} 1-14+\mathrm{H}_{2}$. The pressure-dependence of reaction rate coefficients in these bimolecular reactions is expected to be ignorable according to previous studies [37]. Moreover, the pressure-dependence of rate coefficients of decomposition reactions becomes weak in the investigated temperature range of $500-900 \mathrm{~K}$, as evidenced by $[38,39]$. Therefore, all reaction rate coefficients were initially evaluated at the high-pressure limit and adopted in the kinetic models. Then, the pressure dependence of important reaction pathways filtered by pathway analyses was examined using the RRKM theory by solving the master equation (RRKM-ME) method to investigate if furan formation is pressure dependent in the investigated low-temperature regime. High-pressure limit rate coefficients for reactions with tight transition states were evaluated by transition state theory (TST) based on the frequencies, energy barriers, and molecule information from quantum chemistry calculations. For the barrier-less molecule + radical addition reactions and corresponding dissociation reactions, the reaction rate coefficients were calculated using variational transition state theory (VTST) with the MEP described by the M06-2x/6-311+G(d,p) method. The target C-O bond distance scans were performed with calculation of the optimized structure, energy and vibration frequency at $0.05 \AA$ interval. It was visually confirmed that each point contains a frequency with vibration corresponding to motion along the MEP. The single point energy of each point was further refined using the $\operatorname{CCSD}(\mathrm{T}) / \mathrm{cc}-\mathrm{pvdz}$ method. The rate coefficients of $\mathrm{H}$-atom abstraction reactions of trans-2-butene and cis-2-butene by $\mathrm{H} / \mathrm{OH} / \mathrm{OH} / \mathrm{HO}_{2} / \mathrm{CH}_{3}$ 
radicals were taken from the 2-butene system [40]. In addition, the rate coefficients of the barrierless addition reactions, e.g., $n-\mathrm{C}_{4} \mathrm{H}_{5}+\mathrm{HO}_{2}$ and $n-\mathrm{C}_{4} \mathrm{H}_{5}+\mathrm{OH}$, were chosen by analogy to the benzyl [41] and 1-buten-4-yl [40] systems due to the similarity in the molecular moiety.

The pressure-dependent reaction rate coefficients were calculated in the pressure range of 0.01 $10 \mathrm{~atm}$ and temperature range of 800-2000 K via RRKM-ME using the MultiWell program suite [42]. The maximum energy was set as $300,000 \mathrm{~cm}^{-1}$. In the Multiwell simulations, the translational and vibrational temperatures were assumed to be the same. To accurately describe the sums and densities of states, an energy grain size of $10 \mathrm{~cm}^{-1}$ was used. The collisional energy transfer was described by the temperature-independent exponential-down model $\left(\Delta \mathrm{E}_{\mathrm{down}}=260 \mathrm{~cm}^{-1}\right)$. It is noteworthy that the reaction rate coefficients in the low temperature regime should be less sensitive to the choice of the collisional energy transfer model, as indicated in our previous study [39] where both temperature-independent exponential-down model $\left(\Delta \mathrm{E}_{\text {down }}=260 \mathrm{~cm}^{-1}\right)$ and temperaturedependent exponential-down model $\left(\Delta \mathrm{E}_{\text {down }}=200 \times(\mathrm{T} / 300 \mathrm{~K})^{0.85} \mathrm{~cm}^{-1}\right)$ [43] were examined. Argon was the bath gas collider with Lennard-Jones parameters $\sigma$ and $\varepsilon / k_{B}$ of $3.47 \AA$ and $114 \mathrm{~K}$. The Lennard-Jones parameters of other species were assumed to be the same as those of furan. In the 1,3-butadiene $+\mathrm{OH} \rightarrow$ 2,5-dihydrofuran $(\mathrm{P} 1-8)+\mathrm{H}$ pathway, the loose transition state was utilized to describe the entrance barrier-less 1,3-butadiene $+\mathrm{OH} \rightarrow \mathrm{S} 1-4\left(\mathrm{H}_{2} \mathrm{C}=\mathrm{CH}-\dot{\mathrm{C}} \mathrm{H}-\mathrm{CH}_{2} \mathrm{OH}\right.$, but-1en-3-yl-4-ol) reaction, because similar treatment was used by da Silva et al. [41]. The yield of product was calculated by initiating the S1-4 with chemical activation energy distribution at different temperatures and pressures. The calculation time was long enough for the bimolecular reaction to reach the equilibrium.

The enthalpies of formation at $0 \mathrm{~K}$ were calculated by the atomization method using the $\mathrm{G} 3$ or $\operatorname{CCSD}(\mathrm{T}) / \mathrm{cc}-\mathrm{pvdz}$ methods [44] for new species. The temperature-dependent formation enthalpies, 
entropies, and heat capacities were evaluated by traditional statistical thermodynamics in the MultiWell program suite [42].

\subsection{Jet stirred reactor (JSR) experiments}

The JSR experiments were performed at the Chemical Dynamic Beamline of Advanced Light Source (ALS) at Lawrence Berkeley National Laboratory, California, USA. Detailed descriptions for this setup are available in the literature [45-47], so here is just a brief description. The spherical reactor (volume $33.0 \mathrm{~cm}^{3}$ ) is made of quartz to minimize the surface reactions. MKS mass flow controllers are used to control the residence time by regulating all the gas flows. The gaseous fuel is mixed with argon as diluent, and then the mixture is introduced to the inlet of the reactor via the inner capillary tube. The capillary tube is preheated to 100 Celsius degrees before admission into the reactor. Oxygen with argon as diluent is introduced through the outer channel to the reactor inlet, so oxygen and fuel cannot meet before the reactor. After admission of the reactants, four opposing nozzles are used to create the jet flows, and the jet flows stir the spherical reactor to achieve a homogeneous reaction environment, so the JSR is considered as OD perfectly stirred reactor for simple modeling. An electrically heated oven outside the JSR heats up the reactor to the desired reaction temperatures. A K-type thermocouple (uncertainty of $25 \mathrm{~K}$ ) located on the outside surface of the JSR monitors the reaction temperature, and the temperature inside the reactor was corrected from the measurements following the procedure described by Chen et al. [31]. Sample gas is continuously extracted by a quartz sampling nozzle connected to the time-of-flight molecular beam mass spectrometer (ToF-MBMS) at the reactor exit. Two stages of vacuum pumping are applied to create the pressure differences, and generate the molecular beam to quench further reactions, and minimize the loss of reactive radicals and unstable intermediates in the sample gas. 
A synchrotron vacuum ultraviolet beam is used as photon ionization source to softly ionize the molecules, and signals on the MS are measured for species quantification. The biggest advantage of photon ionization is that the photon energy can be well controlled within the accuracy of 0.01 $\mathrm{eV}$. This feature brings many benefits for species detection and quantification. First, the photon energies for different species can be carefully chosen to minimize the fragmentations and benefit species quantification. A description of the conversion procedure of species signals to mole fractions is available in the literature [31, 45]. Detected and quantified species with their conversion details are listed in Table S1 in the Supplementary Material-4. The estimated experimental uncertainty of species quantification is $20 \%$ for fuel and oxygen, and a factor of 2 for intermediates and products with the measured photon ionization cross sections according to previous literature on the same setup [31]. The photon ionization efficiency (PIE) scans can be performed to identify species by their ionization energies in the database [48]. The experimental uncertainty for photon ionization efficiency (PIE) scan signals is estimated to be $20 \%$. The quantified species at different temperatures from all three experiments account for more than $90 \%$ of the carbon atoms, except at $830 \mathrm{~K}$ in cis-2-butene experiments, where over $80 \%$ is accounted for.

In this work, the JSR experimental conditions are similar among the three fuels: fuel mole fraction of $1.0 \%$, oxygen of $27.5 \%$, argon of $71.5 \%$ for 1,3 -butadiene; fuel mole fraction of $1.0 \%$, oxygen of $30.0 \%$, and argon of $69.0 \%$ for trans-2-butene and cis-2-butene. The reactant compositions are designed to have the same equivalence ratio of 0.2 for all three fuels. The other experimental conditions were residence time of 4.0 seconds, pressure at 700 Torr $(\approx 0.933$ bar $)$, and temperatures from $500 \mathrm{~K}$ to $860 \mathrm{~K}$. The selection of low equivalence ratio and long residence time is to enhance the fuel conversion in the low temperature regime. For safety reason, the argon 
concentration needs to be above $50 \%$ and the oxygen concentration cannot be too high, so leaner conditions were not pursued. Longer residence time is also not chosen since these may compromise the mixing inside the reactor. The three gaseous fuels, 1,3-butadiene, trans-2-butene, and cis-2butene from Sigma-Aldrich have the purity above 99\%. The oxygen and argon from Praxair have the purity above $99.99 \%$.

\subsection{Kinetic modelling}

The base model for the numerical simulation in this study is the $\mathrm{C}_{1}-\mathrm{C}_{4}$ AramcoMech 3.0 model [29]. This model has been validated against the ignition delay time of 1,3-butadiene, trans-2-butene, and cis-2-butene in the low temperature regime. Using the latest NUIGMech model [49] as the base model is not necessary, because its $\mathrm{C}_{4}$ low temperature chemistry is inherited from the AramcoMech 3.0 model. In this work, the proposed furan formation pathways with reaction rate coefficients, and thermodynamics for the new intermediate species were implemented into the base AramcoMech 3.0 model, as shown in Supplementary Material-1. After the implementation, two different treatments were used to test the base model influence. The first one (referred as uniform model) united a number of species that are the same as those in the AramcoMech 3.0 model. The list of duplicated species is presented in Table S2 in the Supplementary Material-4. In the second one (referred as independent model), the species names were kept different to minimize the influence of the base model. Simulation results using both models and the base model are presented to examine the furan formation.

Simulations were performed by ANSYS Chemkin 19.1 software [50]. The conditions for the perfectly stirred reactor model were the same as the experiments. The end time is set arbitrarily as 50 seconds to ensure converged solutions. The rate of production analysis tool in the software package was used to examine the contribution of the proposed reaction pathways. 


\section{Proposed furan formation pathways}

The goal of this work is to explore the furan formation pathways from $\mathrm{C}_{4}$ fuels in the low temperature regime. The oxidant radical addition reactions on one of the two central $\mathrm{C}$ atom of $\mathrm{C}_{4} \mathrm{H}_{\mathrm{x}}(\mathrm{x}=5-8)$ molecules are unlikely to form furan. Therefore, the investigated $\mathrm{H}$-atom abstraction and radical addition reactions are focused on the terminal $\mathrm{C}$ atom in this study. The proposed furan formation pathways starting from $\mathrm{C}_{4} \mathrm{H}_{8}, \mathrm{C}_{4} \mathrm{H}_{7}$, and $\mathrm{C}_{4} \mathrm{H}_{6}$ molecules are investigated, respectively. All nomenclatures of molecules are included in the pathway network in the following figures (Figs. 1,3,5,6).

\subsection{Pathways starting from $\mathrm{H}$-atom abstraction of trans-2-butene}

The furan (P1-9) formation pathway network starting from $\mathrm{H}$-atom abstraction of trans-2-butene (R1-1) is shown in Fig. 1. The H-atom abstraction reactions $\mathrm{R} 1-1+\mathrm{H} \rightleftharpoons \mathrm{S} 1-2+\mathrm{H}_{2}, \mathrm{R} 1-1+\mathrm{O} \rightleftharpoons$ $\mathrm{S} 1-2+\mathrm{OH}, \mathrm{R} 1-1+\mathrm{OH} \rightleftharpoons \mathrm{S} 1-2+\mathrm{H}_{2} \mathrm{O}, \mathrm{R} 1-1+\mathrm{HO}_{2} \rightleftharpoons \mathrm{S} 1-2+\mathrm{H}_{2} \mathrm{O}_{2}$, and $\mathrm{R} 1-1+\mathrm{CH}_{3} \rightleftharpoons \mathrm{S} 1-2+\mathrm{CH}_{4}$ are considered in this study. Many previous studies indicate that $\mathrm{HO}_{2}$ and $\mathrm{OH}$ are the most important radical oxidants at low to intermediate temperatures [41, 51, 52]. Here, the addition of $\mathrm{HO}_{2}$ is considered, followed by $\mathrm{H}_{2} \mathrm{O}$ elimination reaction. The addition reaction of $\mathrm{HO}_{2}$ and $\mathrm{S} 1-2$ radical is barrier-less, which is confirmed by the relaxed scan calculation. The calculated energy monotonically increases with the bond distance between the $\mathrm{O}$ atom of $\mathrm{HO}_{2}$ and the unsaturated $\mathrm{C}$ atom on $\mathrm{S} 1-2$, which is similar to the MEP in benzyl $+\mathrm{HO}_{2}$ system [41]. The $\mathrm{H}_{2} \mathrm{O}$ eliminates from the adduct S1-10 with the energy barrier of $43.6 \mathrm{kcal} / \mathrm{mol}\left(\mathrm{S} 1-10 \rightarrow \mathrm{S} 1-11+\mathrm{H}_{2} \mathrm{O}\right)$. The 2,5dihydrofuran (P1-8) is formed via the pathway of S1-11 $\rightarrow$ S1-12 $\rightarrow$ S1-13 $\rightarrow$ P1-8. This pathway is featured by H-atom transfer $(\mathrm{S} 1-11 \rightarrow \mathrm{S} 1-12,80.1 \mathrm{kcal} / \mathrm{mol}), \mathrm{C}-\mathrm{C}$ rotation $(\mathrm{S} 1-12 \rightarrow \mathrm{S} 1-13,1.9$ $\mathrm{kcal} / \mathrm{mol}$ ), and cyclization $(\mathrm{S} 1-13 \rightarrow \mathrm{P} 1-8,67.4 \mathrm{kcal} / \mathrm{mol})$. In the cyclization reaction $\mathrm{S} 1-13 \rightarrow \mathrm{P} 1-$ 
8, it was observed that the H-atom transfer happens prior to the cyclization (see Fig. 2). Furan (P19) is formed via the dehydrogenation reactions of 2,5-dihydrofuran (P1-8) by either $\mathrm{H}_{2}$ elimination (P1-8 $\rightarrow$ P1-9 $+\mathrm{H}_{2}, 48.6 \mathrm{kcal} / \mathrm{mol}$ ) or $\mathrm{H}$-atom abstraction from $\mathrm{H}, \mathrm{OH}$, and $\mathrm{HO}_{2}$ radicals (e.g., $\mathrm{P} 1$ $\left.8+\mathrm{H} \rightarrow \mathrm{S} 1-14+\mathrm{H}_{2}, 5.4 \mathrm{kcal} / \mathrm{mol} ; \mathrm{S} 1-14 \rightarrow \mathrm{P} 1-9+\mathrm{H}, 32.1 \mathrm{kcal} / \mathrm{mol}\right)$.

\subsection{Pathways starting from $\mathrm{H}$-atom abstraction of 2-butenyl radical}

Instead of the $\mathrm{OH} / \mathrm{HO}_{2}$ addition reactions, the alternative $\mathrm{H}$-atom abstraction reaction of 2butenyl (S1-2) produces 1,3-butadiene (S1-3). Here, the following reactions of $\mathrm{OH}$ and $\mathrm{HO}_{2}$ radical addition to 1,3-butadiene are considered (see Fig. 3). The $\mathrm{OH}$ radical addition reaction is barrier-less (see Fig. 4a), but $\mathrm{HO}_{2}$ addition reaction has tight transition state (see Fig. 4b). Once S1-4 is yielded from $\mathrm{OH}$ radical addition reaction, the furan precursor P1-8 is produced via the pathway of S1-4 $\rightarrow$ S1-5 $\rightarrow$ S1-6 $\rightarrow$ S1-7 $\rightarrow$ P1-8 + H. Reaction S1-4 $\rightarrow$ S1-5 involves H-atom transfer from $\mathrm{OH}$ moiety to the adjacent $\mathrm{C}$ atom with the energy barrier of $40.3 \mathrm{kcal} / \mathrm{mol}$. The reaction S1-5 $\rightarrow$ S1-6 $(2.9 \mathrm{kcal} / \mathrm{mol})$ is featured by $\mathrm{C}-\mathrm{C}$ rotation to facilitate the subsequent cyclization $(\mathrm{S} 1-6 \rightarrow \mathrm{S} 1-7)$. The energy barrier of S1-6 $\rightarrow$ S1-7 reaction is $19.3 \mathrm{kcal} / \mathrm{mol}$, much lower than that of $\mathrm{S} 1-13 \rightarrow \mathrm{P} 1-8(67.6 \mathrm{kcal} / \mathrm{mol}) . \mathrm{S} 1-7 \rightarrow \mathrm{P} 1-8+\mathrm{H}$ is an $\mathrm{H}$-atom elimination reaction with the energy barrier of $36.9 \mathrm{kcal} / \mathrm{mol}$. This value is close to the energy barrier in typical $\mathrm{H}$-atom elimination reaction in hydrogen-abstraction/acetylene-addition pathway $(\sim 38 \mathrm{kcal} / \mathrm{mol})$ [37]. The subsequent pathway of furan formation from P1-8 was discussed before.

If the entrance channel is $\mathrm{HO}_{2}$ addition reaction $\left(\mathrm{S} 1-3+\mathrm{HO}_{2} \rightarrow \mathrm{S} 1-18,11.2 \mathrm{kcal} / \mathrm{mol}\right)$, there are two pathways leading to furan. They are $\mathrm{S} 1-3+\mathrm{HO}_{2} \rightarrow \mathrm{S} 1-18 \rightarrow \mathrm{S} 1-20 \rightarrow \mathrm{S} 1-21 \rightarrow \mathrm{S} 1-13 \rightarrow$ P1-8 $\rightarrow$ P1-9, and S1-3 $+\mathrm{HO}_{2} \rightarrow \mathrm{S} 1-18 \rightarrow \mathrm{S} 1-24 \rightarrow \mathrm{P} 1-8 \rightarrow$ P1-9 as shown in Fig. 3. The following kinetic analysis indicates that the former pathway is less competitive due to the high energy barrier of S1-13 $\rightarrow$ P1-8 $(67.4 \mathrm{kcal} / \mathrm{mol})$, so the latter pathway is dominant. S1-18 $\rightarrow \mathrm{S} 1$ - 
24 is a C-C rotation reaction with the energy barrier of $16.2 \mathrm{kcal} / \mathrm{mol}$ in the pathway of $\mathrm{S} 1-3+$ $\mathrm{HO}_{2} \rightarrow \mathrm{S} 1-18 \rightarrow \mathrm{S} 1-24 \rightarrow \mathrm{P} 1-8+\mathrm{OH} \rightarrow \mathrm{P} 1-9+\mathrm{OH}+\mathrm{H}_{2}$. The following step S1-24 $\rightarrow$ P1-8 $(24.6 \mathrm{kcal} / \mathrm{mol})$ eliminates $\mathrm{OH}$ radical first, and then forms 5-member ring as shown in Fig. 4c. Please note that S1-24 can also be formed if the C-C rotation of S1-3 happens prior to the $\mathrm{HO}_{2}$ addition reaction, which will be included in the pathway network starting from $\mathrm{H}$-atom abstraction of cis-2-butene in section 3.4.

\subsection{Pathways starting from $\mathrm{H}$-atom abstraction of 1,3-butadiene}

The further $\mathrm{H}$-atom abstraction reactions of 1,3-butadiene produce $\mathrm{S} 1-15$, which rapidly converts to S1-16 and S1-22 respectively via the barrier-less addition reactions as shown in Fig. 5. Starting from S1-16, there are two pathways $(\mathrm{S} 1-16 \rightarrow \mathrm{S} 1-17 \rightarrow \mathrm{S} 1-19 \rightarrow \mathrm{S} 1-14 \rightarrow \mathrm{P} 1-9+\mathrm{H}$ and S1-16 $\left.\rightarrow \mathrm{S} 1-17 \rightarrow \mathrm{S} 1-13 \rightarrow \mathrm{P} 1-8 \rightarrow \mathrm{P} 1-9+\mathrm{H}_{2}\right)$ that contribute to furan formation. The main features of the first pathway include $\mathrm{C}-\mathrm{C}$ rotation $(\mathrm{S} 1-16 \rightarrow \mathrm{S} 1-17,5.8 \mathrm{kcal} / \mathrm{mol}), \mathrm{H}$-atom abstraction $(\mathrm{S} 1-17$ $\left.+\mathrm{H} \rightarrow \mathrm{S} 1-19+\mathrm{H}_{2}, 8.0 \mathrm{kcal} / \mathrm{mol}\right)$, cyclization $(\mathrm{S} 1-19 \rightarrow \mathrm{S} 1-14,26.7 \mathrm{kcal} / \mathrm{mol})$, and $\mathrm{H}-\mathrm{atom}$ elimination $(\mathrm{S} 1-14 \rightarrow \mathrm{P} 1-9+\mathrm{H}, 33.8 \mathrm{kcal} / \mathrm{mol})$. The reaction step $\mathrm{S} 1-17+\mathrm{H} \rightarrow \mathrm{S} 1-19+\mathrm{H}_{2}$ in the second pathway has lower energy barrier than the one of S1-17 $\rightarrow \mathrm{S} 1-13(63.4 \mathrm{kcal} / \mathrm{mol})$ in the first pathway, but the requirement for an extra $\mathrm{H}$ radical undermines its contribution.

For the pathway of S1-15 $+\mathrm{HO}_{2} \rightarrow \mathrm{S} 1-22 \rightarrow \mathrm{S} 1-23 \rightarrow \mathrm{S} 1-14+\mathrm{OH} \rightarrow \mathrm{P} 1-9+\mathrm{OH}+\mathrm{H}$ with $\mathrm{HO}_{2}$ addition as entrance channel, the main features are similar to that of $\mathrm{S} 1-3+\mathrm{HO}_{2} \rightarrow \mathrm{S} 1-18 \rightarrow$ $\mathrm{S} 1-24 \rightarrow \mathrm{P} 1-8+\mathrm{OH}$ with cyclization reaction as the rate-determining step. It is also noteworthy that the low concentration of S1-15 in low temperature regime limits its contribution to furan formation. For example, the calculated mole fraction of S1-15 in 1,3-butadiene case is only 1.07 $\times 10^{-11}$ at $800 \mathrm{~K}$. 


\subsection{Pathways starting from cis-2-butene}

To complete the reaction network for furan formation, some possible reaction pathways starting from cis-2-butene (S2-1) to furan are proposed, investigated, and shown in Fig. 6. Generally, once the rotation of the middle $\mathrm{C}-\mathrm{C}$ bond happens $(\mathrm{S} 2-2 \rightarrow \mathrm{S} 1-2, \mathrm{~S} 2-3 \rightarrow \mathrm{S} 1-3)$, the growth network of S2-1 is similar to that of trans-2-butene as discussed before.

\subsection{Calculated rate coefficients of reactions in the pathway network}

Based on the results and discussions in previous sections, the rate coefficients of reactions in the pathway network were calculated and presented in Table 1 in the form of Arrhenius coefficients. The rate validations using the RRKM-ME method were done for the thermal decomposition reaction of phenol and those using the TST method were done for addition reactions of $\mathrm{C}_{2} \mathrm{H}_{2}+$ phenyl and phenyl+ phenylacetylene in our previous studies $[39,53,54]$. Here, the reaction rate coefficients of the $\mathrm{C}_{4} \mathrm{H}_{6}+\mathrm{OH}$ addition reaction using VTST is tested against the values by Bai et al. [55]. As shown in Fig. 7, our results match well with the reported data and the deviation is within $30 \%$. BH\&HLYP/6-311++G(d,p) level of theory is used by Bai et al. [55] to describe the vibrational frequencies, while the M06-2X/6-311G+(d,p) method is used in this study. The rate deviation is likely resulting from the different choice of the calculation method. The updated reaction rate coefficients for $\mathrm{H}$-atom abstraction are listed in Table S3 in the Supplementary Material-4. The Chemkin format of species thermodynamics is provided in the Supplementary Material-2.

Table 1: Reaction rate coefficients of the proposed reaction pathways (Units of E: $\mathrm{kcal} / \mathrm{mol}$ ). Nomenclatures of molecules are included in Figs. 1,3,5,6.

\begin{tabular}{llllll}
\hline No. & Reaction & A & n & E & Comments \\
\hline
\end{tabular}




\begin{tabular}{|c|c|c|c|c|c|}
\hline \multicolumn{6}{|c|}{ Pathways starting from $1,3-\mathrm{C}_{4} \mathrm{H}_{6}$} \\
\hline 1 & $\mathrm{~S} 1-3+\mathrm{OH} \rightarrow \mathrm{S} 1-4$ & $4.2 \times 10^{6}$ & 1.911 & -3.232 & This study \\
\hline-1 & $\mathrm{~S} 1-4 \rightarrow \mathrm{S} 1-3+\mathrm{OH}$ & $1.7 \times 10^{15}$ & -0.244 & 36.80 & This study \\
\hline 2 & $\mathrm{~S} 1-4 \rightarrow \mathrm{S} 1-5$ & $1.7 \times 10^{11}$ & 0.3909 & 35.98 & This study \\
\hline-2 & $\mathrm{~S} 1-5 \rightarrow \mathrm{S} 1-4$ & $3.3 \times 10^{11}$ & 0.3106 & 27.36 & This study \\
\hline 3 & $\mathrm{~S} 1-5 \rightarrow \mathrm{S} 1-6$ & $2.4 \times 10^{12}$ & -0.0022 & 2.89 & This study \\
\hline-3 & $\mathrm{~S} 1-6 \rightarrow \mathrm{S} 1-5$ & $6.7 \times 10^{12}$ & 0.045 & 2 & This study \\
\hline 4 & $\mathrm{~S} 1-6 \rightarrow \mathrm{S} 1-7$ & $2.5 \times 10^{12}$ & -0.06 & 19.3 & This study \\
\hline-4 & $\mathrm{~S} 1-7 \rightarrow \mathrm{S} 1-6$ & $6.1 \times 10^{12}$ & 0.131 & 32.74 & This study \\
\hline 5 & $\mathrm{~S} 1-7 \rightarrow \mathrm{P} 1-8+\mathrm{H}$ & $3.1 \times 10^{11}$ & 0.7598 & 37.92 & This study \\
\hline-5 & $\mathrm{P} 1-8+\mathrm{H} \rightarrow \mathrm{S} 1-7$ & $3.4 \times 10^{8}$ & 1.508 & 4.22 & This study \\
\hline 6 & $\mathrm{P} 1-8 \rightarrow \mathrm{P} 1-9+\mathrm{H}_{2}$ & $3.5 \times 10^{7}$ & 1.475 & 41.86 & This study \\
\hline-6 & $\mathrm{P} 1-9+\mathrm{H}_{2} \rightarrow \mathrm{P} 1-8$ & $2.9 \times 10^{1}$ & 2.926 & 40.84 & This study \\
\hline 7 & $\mathrm{P} 1-8+\mathrm{H} \rightarrow \mathrm{S} 1-14+\mathrm{H}_{2}$ & $6.0 \times 10^{7}$ & 1.753 & 3.23 & This study \\
\hline-7 & $\mathrm{~S} 1-14+\mathrm{H}_{2} \rightarrow \mathrm{P} 1-8+\mathrm{H}$ & $2.8 \times 10^{4}$ & 2.462 & 26.02 & This study \\
\hline 8 & $\mathrm{~S} 1-14 \rightarrow \mathrm{P} 1-9+\mathrm{H}$ & $2.4 \times 10^{11}$ & 0.7632 & 28.42 & This study \\
\hline-8 & $\mathrm{P} 1-9+\mathrm{H} \rightarrow \mathrm{S} 1-14$ & $7.8 \times 10^{8}$ & 1.434 & 4.42 & This study \\
\hline 9 & $\mathrm{P} 1-8+\mathrm{O}_{2} \rightarrow \mathrm{S} 1-14+\mathrm{HO}_{2}$ & $2.4 \times 10^{1}$ & 3.207 & 4.46 & This study \\
\hline-9 & $\mathrm{~S} 1-14+\mathrm{HO}_{2} \rightarrow \mathrm{P} 1-8+\mathrm{O}_{2}$ & $6.8 \times 10^{-2}$ & 3.403 & 15.3 & This study \\
\hline 10 & $\begin{array}{l}\mathrm{P} 1-8+\mathrm{HO}_{2} \rightleftharpoons \\
\mathrm{S} 1-14+\mathrm{H}_{2} \mathrm{O}_{2}\end{array}$ & $6.3 \times 10^{1}$ & 3.37 & 13.72 & $\begin{array}{l}\text { Analogy to } \mathrm{C}_{3} \mathrm{H}_{8}+\mathrm{HO}_{2} \rightleftharpoons \mathrm{C}_{3} \mathrm{H}_{7}+\mathrm{H}_{2} \mathrm{O}_{2} \\
{[40]}\end{array}$ \\
\hline 11 & $\mathrm{P} 1-8+\mathrm{OH} \rightleftharpoons \mathrm{S} 1-14+\mathrm{H}_{2} \mathrm{O}$ & $4.7 \times 10^{7}$ & 1.61 & -0.035 & $\begin{array}{l}\text { Analogy to } \mathrm{C}_{3} \mathrm{H}_{8}+\mathrm{OH} \rightleftharpoons \mathrm{C}_{3} \mathrm{H}_{7}+\mathrm{H}_{2} \mathrm{O} \\
{[40]}\end{array}$ \\
\hline 12 & $\mathrm{~S} 1-3+\mathrm{HO}_{2} \rightarrow \mathrm{S} 1-18$ & $1.1 \times 10^{2}$ & 3.047 & 11.2 & This study \\
\hline-12 & $\mathrm{~S} 1-18 \rightarrow \mathrm{S} 1-3+\mathrm{HO}_{2}$ & $2.5 \times 10^{13}$ & 0.085 & 21.8 & This study \\
\hline 13 & $\mathrm{~S} 1-18 \rightarrow \mathrm{S} 1-20+\mathrm{OH}$ & $5.6 \times 10^{12}$ & 0.2055 & 12.95 & This study \\
\hline-13 & $\mathrm{~S} 1-20+\mathrm{OH} \rightarrow \mathrm{S} 1-18$ & $2.9 \times 10^{4}$ & 2.588 & 25.1 & This study \\
\hline 14 & $\mathrm{~S} 1-20 \rightarrow \mathrm{S} 1-21$ & $1.7 \times 10^{12}$ & 0.41 & 33.58 & This study \\
\hline-14 & $\mathrm{~S} 1-21 \rightarrow \mathrm{S} 1-20$ & $1.8 \times 10^{11}$ & 0.4216 & 59.58 & This study \\
\hline 15 & $\mathrm{~S} 1-21 \rightarrow \mathrm{S} 1-13$ & $3.7 \times 10^{12}$ & -0.0259 & 2.198 & This study \\
\hline-15 & $\mathrm{~S} 1-13 \rightarrow \mathrm{S} 1-21$ & $5.0 \times 10^{12}$ & -0.0465 & 0.712 & This study \\
\hline 16 & $\mathrm{~S} 1-18 \rightarrow \mathrm{S} 1-24$ & $1.9 \times 10^{13}$ & -0.011 & 9.0 & This study \\
\hline-16 & $\mathrm{~S} 1-24 \rightarrow \mathrm{S} 1-18$ & $9.9 \times 10^{12}$ & -0.0003 & 13.13 & This study \\
\hline 17 & $\mathrm{~S} 1-24 \rightarrow \mathrm{P} 1-8+\mathrm{OH}$ & $8.0 \times 10^{11}$ & 0.3419 & 23.12 & This study \\
\hline-17 & $\mathrm{P} 1-8+\mathrm{OH} \rightarrow \mathrm{S} 1-24$ & $2.9 \times 10^{4}$ & 2.8 & 46.7 & This study \\
\hline \multicolumn{6}{|c|}{ Pathway starting from tran-2- $\mathrm{C}_{4} \mathrm{H}_{7}$} \\
\hline 18 & $\mathrm{~S} 1-2+\mathrm{HO}_{2} \rightleftharpoons \mathrm{S} 1-10$ & $8.2 \times 10^{4}$ & 2.2 & -5.13 & $\begin{array}{l}\text { Analogy to benzyl }+\mathrm{HO}_{2} \gtrless \\
\text { benzylhydroperoxide [41] }\end{array}$ \\
\hline 18 & $\mathrm{~S} 1-10 \rightarrow \mathrm{S} 1-11+\mathrm{H}_{2} \mathrm{O}$ & $7.0 \times 10^{9}$ & 1.026 & 37.2 & This study \\
\hline-19 & $\mathrm{~S} 1-11+\mathrm{H}_{2} \mathrm{O} \rightarrow \mathrm{S} 1-10$ & $5.1 \times 10^{-26}$ & 3.888 & 97.44 & This study \\
\hline 19 & $\mathrm{~S} 1-11 \rightarrow \mathrm{S} 1-12$ & $6.6 \times 10^{7}$ & 1.465 & 74.1 & This study \\
\hline-20 & $\mathrm{~S} 1-12 \rightarrow \mathrm{S} 1-11$ & $7.5 \times 10^{7}$ & 1.405 & 69.52 & This study \\
\hline 20 & $\mathrm{~S} 1-12 \rightarrow \mathrm{S} 1-13$ & $4.1 \times 10^{10}$ & 0.037 & 1.4 & This study \\
\hline-21 & $\mathrm{~S} 1-13 \rightarrow \mathrm{S} 1-12$ & $1.7 \times 10^{13}$ & -0.204 & 1.02 & This study \\
\hline 21 & $\mathrm{~S} 1-13 \rightarrow \mathrm{P} 1-8$ & $6.7 \times 10^{10}$ & 0.402 & 66.1 & This study \\
\hline-22 & $\mathrm{P} 1-8 \rightarrow \mathrm{S} 1-13$ & $1.6 \times 10^{12}$ & 0.511 & 56.8 & This study \\
\hline \multicolumn{6}{|c|}{ Pathways starting from $\mathrm{N}-\mathrm{C}_{4} \mathrm{H}_{5}$} \\
\hline 22 & $\mathrm{~S} 1-15+\mathrm{OH} \rightleftharpoons \mathrm{S} 1-16$ & $3.0 \times 10^{13}$ & 0 & 0 & $\begin{array}{l}\text { Analogy to } \mathrm{IC}_{4} \mathrm{H}_{7}+\mathrm{OH} \rightleftharpoons \mathrm{IC}_{4} \mathrm{H}_{7} \mathrm{OH} \\
{[40]}\end{array}$ \\
\hline 23 & $\mathrm{~S} 1-16 \rightarrow \mathrm{S} 1-17$ & $3.2 \times 10^{12}$ & 0.0615 & 5.7 & This study \\
\hline-23 & $\mathrm{~S} 1-17 \rightarrow \mathrm{S} 1-16$ & $2.6 \times 10^{12}$ & 0.125 & 3.1 & This study \\
\hline 24 & $\mathrm{~S} 1-17 \rightarrow \mathrm{S} 1-13$ & $1.9 \times 10^{10}$ & 0.7917 & 58.9 & This study \\
\hline-24 & $\mathrm{~S} 1-13 \rightarrow \mathrm{S} 1-17$ & $1.5 \times 10^{10}$ & 0.771 & 70.2 & This study \\
\hline
\end{tabular}




\begin{tabular}{|c|c|c|c|c|c|}
\hline 25 & $\mathrm{~S} 1-17+\mathrm{H} \rightarrow \mathrm{S} 1-19+\mathrm{H}_{2}$ & $8.0 \times 10^{6}$ & 1.941 & 4.6 & This study \\
\hline-25 & $\mathrm{~S} 1-19+\mathrm{H}_{2} \rightarrow \mathrm{S} 1-17+\mathrm{H}$ & $2.0 \times 10^{3}$ & 2.812 & 37.1 & This study \\
\hline 26 & $\mathrm{~S} 1-19 \rightarrow \mathrm{S} 1-14$ & $5.2 \times 10^{11}$ & 0.091 & 23.96 & This study \\
\hline-26 & S1-14 $\rightarrow$ S1-19 & $5.8 \times 10^{12}$ & 0.15 & 19.05 & This study \\
\hline 27 & $\mathrm{~S} 1-15+\mathrm{HO}_{2} \rightleftharpoons \mathrm{S} 1-22$ & $8.2 \times 10^{4}$ & 2.2 & -5.13 & $\begin{array}{l}\text { Analogy to benzyl }+\mathrm{HO}_{2} \gtrless \\
\text { benzylhydroperoxide [41] }\end{array}$ \\
\hline 28 & $\mathrm{~S} 1-22 \rightarrow \mathrm{S} 1-23$ & $7.2 \times 10^{12}$ & -0.0068 & 5.06 & This study \\
\hline-28 & $\mathrm{~S} 1-23 \rightarrow \mathrm{S} 1-22$ & $3.3 \times 10^{12}$ & 0.0561 & 7.91 & This study \\
\hline 29 & $\mathrm{~S} 1-23 \rightarrow \mathrm{S} 1-14$ & $3.0 \times 10^{11}$ & 0.3345 & 33.1 & This study \\
\hline-29 & $\mathrm{~S} 1-14 \rightarrow \mathrm{S} 1-23$ & $4.8 \times 10^{3}$ & 2.446 & 22.9 & This study \\
\hline \multicolumn{6}{|c|}{ Pathways starting from cis-2- $\mathrm{C}_{4} \mathrm{H}_{7}$} \\
\hline 30 & $\mathrm{~S} 2-2+\mathrm{HO}_{2} \rightleftharpoons \mathrm{S} 2-5$ & $8.2 \times 10^{4}$ & 2.2 & -5.13 & $\begin{array}{l}\text { Analogy to benzyl+}+\mathrm{HO}_{2} \rightleftharpoons \\
\text { benzylhydroperoxide [41] }\end{array}$ \\
\hline 31 & $\mathrm{~S} 2-5 \rightarrow \mathrm{S} 2-6+\mathrm{H}_{2} \mathrm{O}$ & $6.8 \times 10^{7}$ & 1.218 & 41.58 & This study \\
\hline-31 & $\mathrm{~S} 2-6+\mathrm{H}_{2} \mathrm{O} \rightarrow \mathrm{S} 2-5$ & $4.9 \times 10^{3}$ & 3.98 & 74.8 & This study \\
\hline 32 & $\mathrm{~S} 2-5 \rightarrow \mathrm{S} 2-7+\mathrm{H}_{2} \mathrm{O}$ & $1.3 \times 10^{10}$ & 0.991 & 36.4 & This study \\
\hline-32 & $\mathrm{~S} 2-7+\mathrm{H}_{2} \mathrm{O} \rightarrow \mathrm{S} 2-5$ & $5.2 \times 10^{-2}$ & 3.799 & 97.9 & This study \\
\hline 33 & $\mathrm{~S} 2-6 \rightarrow \mathrm{S} 2-7$ & $3.8 \times 10^{10}$ & 0.811 & 56.2 & This study \\
\hline-33 & $\mathrm{~S} 2-7 \rightarrow \mathrm{S} 2-6$ & $2.1 \times 10^{9}$ & 0.8576 & 84.8 & This study \\
\hline 34 & $\mathrm{~S} 2-3 \rightarrow \mathrm{S} 2-4$ & $3.5 \times 10^{11}$ & 0.234 & 41.6 & This study \\
\hline-34 & $\mathrm{~S} 2-4 \rightarrow \mathrm{S} 2-3$ & $3.9 \times 10^{12}$ & 0.276 & 32.42 & This study \\
\hline 35 & $\mathrm{~S} 1-2 \rightarrow \mathrm{S} 2-2$ & $1.4 \times 10^{13}$ & 0.0519 & 14.4 & This study \\
\hline-35 & $\mathrm{~S} 2-2 \rightarrow \mathrm{S} 1-2$ & $4.9 \times 10^{12}$ & 0.0663 & 13.1 & This study \\
\hline 36 & $\mathrm{~S} 2-2+\mathrm{HO}_{2} \rightarrow \mathrm{S} 1-24$ & $1.7 \times 10^{2}$ & 3.007 & 11.5 & This study \\
\hline-36 & $\mathrm{~S} 1-24 \rightarrow \mathrm{S} 2-2+\mathrm{HO}_{2}$ & $9.1 \times 10^{12}$ & 0.1938 & 22.57 & This study \\
\hline 37 & $\mathrm{~S} 2-3 \rightarrow \mathrm{S} 1-3$ & $1.1 \times 10^{13}$ & -0.1003 & 2.794 & This study \\
\hline-37 & $\mathrm{~S} 1-3 \rightarrow \mathrm{S} 2-3$ & $1.5 \times 10^{13}$ & -0.1 & 5.704 & This study \\
\hline
\end{tabular}

\section{Examination of furan formation pathways}

In this section, experimental identification of furan is presented first, followed by the concentration profiles comparison between experiments and simulations using the AramcoMech 3.0 model, the independent model and the uniform model. Please note that the temperatures were shifted $30 \mathrm{~K}$ lower to compensate the effect of cooling water on the sampling probe and probe perturbation, which follows the procedure in the literature on the same experimental setup $[31,56]$. Pathway analyses are presented later to indicate their contribution to fuel consumption and furan formation. Furthermore, the influence of uncertainty originating from rate coefficient calculations of the key reaction $\mathrm{C}_{4} \mathrm{H}_{6}+\mathrm{HO}_{2} \rightleftharpoons \mathrm{S} 1-18\left(\mathrm{C}_{4} \mathrm{H}_{6} 1-3 \mathrm{OOH} 4\right)$ on model prediction is discussed in the 
uniform model. All of the speciation data from experiments are available in Supplementary Material-3.

\subsection{Furan identification and quantification by experiments, and predictions by simulations}

\subsubsection{Experimental identification of furan}

To identify furan, PIE scans were performed in 1,3-butadiene and trans-2-butene experiments as shown in Fig. 8, but not for cis-2-butene experiment because of the low signals of $\mathrm{C}_{4} \mathrm{H}_{4} \mathrm{O}$. The PIE scan was performed from $8.50 \mathrm{eV}$ to $10.50 \mathrm{eV}$ with $0.05 \mathrm{eV}$ per step at a reaction temperature of $830 \mathrm{~K}$ to achieve large signals of $\mathrm{C}_{4} \mathrm{H}_{4} \mathrm{O}$. It is observed that the onset in both 1,3-butadiene and trans-2-butene experiments is $8.85 \mathrm{eV}$. The match of this onset with the ionization energy of furan (onset: $8.88 \mathrm{eV}$ [57]), and the fitting curves of furan photon ionization cross section in the database [57] both identify $\mathrm{C}_{4} \mathrm{H}_{4} \mathrm{O}$ as furan. Other isomers with molecular formula of $\mathrm{C}_{4} \mathrm{H}_{4} \mathrm{O}$ are less probable than furan, because their molecular structures are too difficult to be formed, and they have different ionization energies. Table S4 in the Supplementary Material-2 lists a few conceivable isomers with the molecular formula of $\mathrm{C}_{4} \mathrm{H}_{4} \mathrm{O}$.

\subsubsection{Predictions of furan in 1,3-butadiene, cis-2-butene, and trans-2-butene experiments}

The examination of the proposed furan formation pathways is described in this section. Mole fraction profiles of furan vs temperature were compared and presented in Fig. 9 for all three fuels. Scattered points are from experiments, and lines with different colors and styles represent different kinetic models. Among the three fuels, 1,3-butadiene produces the highest furan concentrations, which is followed by trans-2-butene. Cis-2-butene has lowest furan formation by both experiments and simulations in the low temperature regime. The differences of furan formation among the three fuels suggest that most of the furan is originated from 1,3-butadiene, and the furan formation from 
trans-2-butene and cis-2-butene is minor. Both predictions by the uniform model and the independent model show good agreement for furan formation in the 1,3-butadiene case with some minor differences, but the AramcoMech 3.0 model did not. Note that in the 1,3-butadiene case, the trends of profiles using both updated models differ between experiment and simulation. However, the simulation results fall into the experimental uncertainty range, which means major furan formation pathways are covered. For the trans-2-butene case, the experimental data have higher values than simulations, although the quantified furan concentration is low. The concentrations of furan are near the detection limit of the device (10 ppm), which may be responsible for the mismatch.

The dominant furan formation pathway in the AramcoMech 3.0 model is dehydrogenation of 2,5-dihydrofuran $\left(\mathrm{C}_{4} \mathrm{H}_{6} \mathrm{O} 25\right)$. The 2,5-dihydrofuran is produced from cyclization of but-1-en-3-yl4-peroxide $\left(\mathrm{C}_{4} \mathrm{H}_{6} 1-3 \mathrm{OOH} 4\right)$, which can be traced back to but-3-en-1-yl radical $\left(\mathrm{C}_{4} \mathrm{H}_{7} 1-3\right)$ and $\mathrm{C}_{4} \mathrm{H}_{6}$. The under-prediction of the 2,5-dihydrofuran mole fraction causes under-prediction of furan in the AramcoMech 3.0 model. In the independent and uniform models, more complete furan formation networks (see Figs. 1, 3, 5, 6) are proposed, and the improvements substantiate the importance of the proposed furan formation pathways.

\subsection{Influence of proposed pathways on fuel consumption}

The fuel reactivity is sensitive to $\mathrm{OH}$ and $\mathrm{HO}_{2}$ radical concentrations in the low temperature regime, where the $\mathrm{OH}$ and $\mathrm{HO}_{2}$ radicals trigger the chain reactions. The furan formation is also initiated by $\mathrm{OH}$ and $\mathrm{HO}_{2}$ radicals, which might influence the radical pool and hence the fuel consumption. Therefore, the influence of proposed pathways on fuel consumption rates is examined in this section. Figure 10 shows the comparison among experiments and three model predictions for the fuels in all three cases. The AramcoMech 3.0 model over-predicted the fuel 
consumption rates in the low temperature regime, and it is improved in the uniform model and the independent model. The over-prediction of fuel reactivity is also observed in the ignition delay time measurements at 10 bar for 1,3-butadiene [29], trans-2-butene, and cis-2-butene [40] in the low temperature regime. The fuel consumption is higher for the uniform model than for the independent model, but furan concentrations only have minor differences as shown in Fig. 9. Therefore, it can be suggested that the influence of fuel consumption rates on furan formation is minor, and the fuel is dominantly consumed by other pathways instead of the proposed furan formation pathways. Additional support for this statement is provided in product profiles and pathway analyses in the later sections.

The main reason for the reduced fuel consumption could be the separate treatment and updated rate constants for $\mathrm{H}$-atom abstraction of trans-2-butene and cis-2-butene in the uniform and independent models, and the competitive $\mathrm{OH}$ and $\mathrm{HO}_{2}$ addition reactions in the proposed pathway may have minor effects in the 1,3-butadiene case. Further investigations on the fuel consumption reaction rates are necessary for better predictions of 1,3-butadiene, trans-2-butene and cis-2-butene consumption in the low temperature regime.

\subsection{Influence of the proposed pathways on main products and intermediates predictions}

In this section, the influence of the proposed pathway on main products and intermediates is examined. The comparison of experiments and three model simulations for the main products, e.g. $\mathrm{H}_{2} \mathrm{O}, \mathrm{CO}$, and $\mathrm{CO}_{2}$ are presented in Fig. 11, and key intermediates, e.g. formaldehyde and acetaldehyde are presented in Fig. 12. Ethylene, propene, and 1,3-butadiene are presented in Figs. S1 and S2 in Supplementary Material-4. In general, the independent model and the uniform model both have better predictions for most of the species than the AramcoMech 3.0 model, except that $\mathrm{CO}_{2}$ in the trans-2-butene case is under-predicted. For the main products and intermediates, one 
possible reason is the reduced fuel consumption. For some intermediates like acetaldehyde, another possible reason is the competitiveness of the proposed $\mathrm{OH}$ and $\mathrm{HO}_{2}$ addition pathways. For example, the Waddington pathway [58] to produce acetaldehyde in trans-2-butene and cis-2butene cases is undermined by the proposed $\mathrm{OH}$ addition reactions, so the acetaldehyde production is reduced. Further investigations are necessary for model optimization.

\subsection{Pathway analyses}

In this section, pathway analyses are performed to indicate the contribution of the proposed pathways to furan formation and fuel consumption. From the pathway analysis for furan, the main production pathway is the barrier-less $\mathrm{OH}$ addition pathway to produce $\mathrm{S} 1-4$, and $\mathrm{HO}_{2}$ addition pathway with high energy barrier only has a minor effect. It is also found that the equilibrium constant for $\mathrm{C}_{4} \mathrm{H}_{6}+\mathrm{OH} \rightleftharpoons \mathrm{S} 1-4$ is critical for furan formation, which is determined by the calculated forward and reverse reaction rates in this work.

To examine the contribution of the proposed pathway to fuel consumption, pathway analysis is performed for 1,3-butadiene. The results are presented in Fig. 13 for the top five consumption pathways. It can be found that the $\mathrm{OH}$ addition reaction at $800 \mathrm{~K}$ only consumes $2.4 \%$ and $2.6 \%$ in the uniform model and the independent model, respectively, and $\mathrm{HO}_{2}$ addition reaction has lower contribution. This observation further supports the previous statement that the influence of the base model is minor on furan formation, but the reactions of $\mathrm{C}_{4} \mathrm{H}_{6}+\mathrm{OH} \rightleftharpoons \mathrm{S} 1-4$ and $\mathrm{C}_{4} \mathrm{H}_{6}+$ $\mathrm{HO}_{2} \rightleftharpoons \mathrm{S} 1-18$ may have minor effects on the fuel consumption. Similar observations are obtained in the recent studies of $\mathrm{OH}$ and $\mathrm{HO}_{2}$ addition on 1,3-butadiene [55, 59]. It is noteworthy that since only $10 \%$ of fuel is consumed in experiments, the actual effect on furan emission could be minor. 
The rate of $\mathrm{C}_{4} \mathrm{H}_{6}+\mathrm{HO}_{2} \rightleftharpoons \mathrm{S} 1-18$ reaction is sensitive to the energy barrier in the low temperature regime. For example, a deviation of $2.0 \mathrm{kcal} / \mathrm{mol}$ in the energy barrier results in the uncertainty of rate coefficient by a factor of 4.2 at $700 \mathrm{~K}$. Motivated by the big deviation $(5.3 \mathrm{kcal} / \mathrm{mol})$ of the forward reaction energy barriers calculated by the CCSD(T)/cc-pvdz and G3 methods, other highlevel methods including the $\mathrm{CCSD}(\mathrm{T}) / \mathrm{CBS}$, CBS-ANPO, and G4 methods were applied to reevaluate the energy barrier, and the results are shown in Table 2. The energy barrier of forward reaction predicted by the $\mathrm{G} 4$ method is $11.2 \mathrm{kcal} / \mathrm{mol}$, which is close to the value predicted by the $\operatorname{CCSD}(\mathrm{T}) / \mathrm{CBS}$ method $(11.8 \mathrm{kcal} / \mathrm{mol})$. Given that the $\mathrm{G} 4$ and $\operatorname{CCSD}(\mathrm{T}) / \mathrm{CBS}$ methods are generally considered as benchmark methods in energy calculations [60], the value of $11.2 \mathrm{kcal} / \mathrm{mol}$ by the G4 method is adopted in this study. The influence of different energy barrier calculated by different methods in both forward and reverse reactions is presented in Fig. 14 for furan and 1,3butadiene to reveal the influence of the uncertainty using the uniform model. If the energy barrier is $8.1 \mathrm{kcal} / \mathrm{mol}$ predicted by the G3 and DFT/B3LYP/6-311+G(d,p) methods, the furan formation is enhanced with over-predicted fuel consumption rate in the temperature range of 700-800 K. On the contrary, the fuel consumption rate prediction slightly improves at the cost of furan prediction if the energy barrier is $13.4 \mathrm{kcal} / \mathrm{mol}$ calculated by the $\operatorname{CCSD}(\mathrm{T}) / \mathrm{cc}-\mathrm{pvdz}$ method. The energy barrier calculated by the G4 method has the best predictions for both furan and fuel predictions (see Fig. 14).

Table 2. Comparisons of the calculated energy barriers ( $\mathrm{kcal} / \mathrm{mol})$ using different methods for forward reaction of $\mathrm{C}_{4} \mathrm{H}_{6}+\mathrm{HO}_{2} \rightleftharpoons \mathrm{S} 1-18$.

\begin{tabular}{|c|c|c|c|c|c|c|c|}
\hline \multirow[b]{2}{*}{$\begin{array}{l}\text { DFT/BYLYP/ } \\
6-311+G(d, p)\end{array}$} & \multicolumn{4}{|c|}{$\operatorname{CCSD}(\mathrm{T})$} & \multirow[b]{2}{*}{ CBS-ANPO } & \multirow[b]{2}{*}{ G3 } & \multirow[b]{2}{*}{ G4 } \\
\hline & cc-pVDZ & pVTZ & cc-pVQZ & CBS & & & \\
\hline 8.1 & 13.4 & 12.3 & 11.9 & 11.8 & 9.5 & 8.1 & 11.2 \\
\hline
\end{tabular}


The high-pressure limit reaction rate coefficients were used in the above analyses, where the results indicate that $\mathrm{C}_{4} \mathrm{H}_{6}(\mathrm{~S} 1-3)+\mathrm{OH} \rightarrow \mathrm{S} 1-4 \rightarrow \mathrm{S} 1-5 \rightarrow \mathrm{S} 1-6 \rightarrow \mathrm{S} 1-7 \rightarrow \mathrm{P} 1-8 \rightarrow$ furan $(\mathrm{P} 1-9)$ is the dominant pathway for furan formation. The pressure dependence for this pathway is investigated here in the temperature range of $800-2000 \mathrm{~K}$. The pressure dependence at lower temperature is not pursued, since the calculations become time-consuming due to low reaction rates. The results shown in Fig. 15 suggest that the furan formation is pressure independent when the temperature is below $1000 \mathrm{~K}$. The yield of P1-8 in the bimolecular reaction $\mathrm{S} 1-3+\mathrm{OH} \rightarrow \mathrm{P} 1-$ $8+\mathrm{H}$ system linearly increases with temperature, but are independent with pressure, as shown in Fig. 15a. For the $\mathrm{H}_{2}$ elimination reaction $\mathrm{P} 1-8 \rightarrow \mathrm{P} 1-9+\mathrm{H}_{2}$, its reaction rate is pressure dependent in the temperature range of $1100-2000 \mathrm{~K}$ and becomes insensitive at lower temperatures. The conclusion from Fig. 15 indicates that the above analyses using high-pressure limit reaction rate are valid at different pressures in the low temperature regime.

\section{Conclusions}

In this work, furan formation pathways originated from 1,3-butadiene, trans-2-butene, and cis2-butene are proposed. Potential energy surfaces, reaction rate coefficients of the proposed pathways, and the thermodynamics of new species were evaluated by high level theories of quantum chemistry. The proposed reaction pathways were implemented into the latest AramcoMech 3.0 model to evaluate the prediction performance with the experimental data. Two treatments (uniform model and independent model) were applied to test the base model influence on furan formation predictions.

The experiments were performed in a JSR coupled with ToF-MBMS using synchrotron ultra violet radiation as photon ionization source, which allows in-situ species identification and 
quantification. Furan was identified by the its ionization energy onset and PIE curve. The temperature versus mole fraction profiles of furan were well captured and improved by both uniform and independent models compared to the AramcoMech 3.0 base model. The improvement of furan predictions is mainly attributed to the updated $\mathrm{H}$-atom abstraction rate, and the addition of the proposed reaction pathways, e.g. $\mathrm{OH}$ and $\mathrm{HO}_{2}$ addition to 1,3-butadiene. The comparison between the simulation results using the uniform and the independent model indicates that furan formation is less influenced by the base model.

The pathway analysis for furan in the 1,3-butadiene case indicates that furan formation mainly comes from the barrier-less $\mathrm{OH}$ addition reactions to 1,3-butadiene in the proposed pathways. Pathway analysis for the fuel indicates that both 1,3-butadiene $+\mathrm{OH}$ and 1,3-butadiene $+\mathrm{HO}_{2}$ addition pathways have some effects on fuel consumption. Further analyses were performed with the energy barrier of the 1,3-butadiene $+\mathrm{HO}_{2}$ addition reaction by different level of theories in quantum chemistry to reveal the influence of calculated rate-coefficient uncertainty on model predictions. Calculations under different pressures indicate the pressure independence of the proposed pathways in the low temperature regime. Instead of proposing a new model, this work aims at proposing and examining furan formation pathways to further the understanding of furan formation chemistry in low temperature regime.

\section{Acknowledgements}

This work was performed as part of the Cluster of Excellence "The Fuel Science Center", which is funded by the Deutsche Forschungsgemeinschaft (DFG, German Research Foundation) under Germany's Excellence Strategy - Exzellenzcluster 2186 "The Fuel Science Center” ID: 390919832. The research reported in this paper was supported by funding from the King Abdullah 
University of Science and Technology (KAUST) and the Clean Combustion Research Center (CCRC). NH acknowledges support from the U.S. DOE, Office of Science, Office of Basic Energy Sciences. Sandia National Laboratories is a multi-mission laboratory managed and operated by National Technology and Engineering Solutions of Sandia, LLC., a wholly owned subsidiary of Honeywell International, Inc., for the U.S. DOE National Nuclear Security Administration under contract DE-NA0003525. The Advanced Light Source is supported by the Director, Office of Science, Office of Basic Energy Sciences, of the U.S. DOE under Contract No. DEAC0205CH11231. This paper describes objective technical results and analysis. Any subjective views or opinions that might be expressed in the paper do not necessarily represent the views of the USDOE or the US Government.

\section{References}

1. N. Bakhiya, K.E. Appel, Toxicity and carcinogenicity of furan in human diet. Arch. Toxicol., 84 (2010) 563-578.

2. L.A. Peterson, Electrophilic intermediates produced by bioactivation of furan. Drug Metab. Rev., 38 (2006) 615-626.

3. V. Ravindranath, L.T. Burka, M.R. Boyd, Reactive metabolites from the bioactivation of toxic methylfurans. Science, 224 (1984) 884-886.

4. Toxicology and Carcinogenesis Studies of Furan (CAS No. 110-00-9) in F344 Rats and B6C3F1 Mice (Gavage Studies), National Toxicology Program technical report series 402. 1993: National Toxicology Program.

5. International Agency for Cancer Research: IARC Monographs on the Evaluation of Carcinogenic Risks to Humans, Internal Report 14/002. Report of the Advisory Group to Recommend Priorities. 2014: World Health Organization.

6. K.O. Johansson, T. Dillstrom, M. Monti, F. El Gabaly, M.F. Campbell, P.E. Schrader, D.M. Popolan-Vaida, N.K. Richards-Henderson, K.R. Wilson, A. Violi, Formation and emission of large furans and oxygenated hydrocarbons from flames. Proc. Nat. Acad. Sci., 113 (2016) 8374-8379.

7. P. Liu, B. Chen, Z. Li, A. Bennett, S. Sioud, S.M. Sarathy, W.L. Roberts, Evolution of oxygenated polycyclic aromatic hydrocarbon chemistry at flame temperatures. Combust. Flame, 209 (2019) 441-451.

8. P. Liu, B. Chen, Z. Li, A. Bennett, S. Sioud, H. Pitsch, S.M. Sarathy, W.L. Roberts, Experimental and theoretical evidence for the temperature-determined evolution of PAH functional groups. Proc. Combust. Inst., 38 (2021) 1467-1475. 
9. J. Cain, A. Laskin, M.R. Kholghy, M.J. Thomson, H. Wang, Molecular characterization of organic content of soot along the centerline of a coflow diffusion flame. Phys. Chem. Chem. Phys., 16 (2014) 25862-25875.

10. N.N. Mustafi, R.R. Raine, B. James, Characterization of exhaust particulates from a dual fuel engine by TGA, XPS, and Raman techniques. Aerosol Sci. Tech., 44 (2010) 954-963.

11. C.K. Gaddam, R.L. Vander Wal, Physical and chemical characterization of SIDI engine particulates. Combust. Flame, 160 (2013) 2517-2528.

12. M. Commodo, G. De Falco, R. Larciprete, A. D'Anna, P. Minutolo, On the hydrophilic/hydrophobic character of carbonaceous nanoparticles formed in laminar premixed flames. Exp. Therm. Fluid, 73 (2016) 56-63.

13. T.C. Bond, S.J. Doherty, D.W. Fahey, P.M. Forster, T. Berntsen, B.J. DeAngelo, M.G. Flanner, S. Ghan, B. Kärcher, D. Koch, Bounding the role of black carbon in the climate system: A scientific assessment. J. Geophys. Res. Atmos., 118 (2013) 5380-5552.

14. R. Zhang, A.F. Khalizov, J. Pagels, D. Zhang, H. Xue, P.H. McMurry, Variability in morphology, hygroscopicity, and optical properties of soot aerosols during atmospheric processing. Proc. Nat. Acad. Sci., 105 (2008) 10291-10296.

15. V. Ramanathan, C. Chung, D. Kim, T. Bettge, L. Buja, J. Kiehl, W. Washington, Q. Fu, D. Sikka, M. Wild, Atmospheric brown clouds: Impacts on South Asian climate and hydrological cycle. Proc. Nat. Acad. Sci., 102 (2005) 5326-5333.

16. H. Chagger, A. Kendall, A. McDonald, M. Pourkashanian, A. Williams, Formation of dioxins and other semi-volatile organic compounds in biomass combustion. Appl. Energy, 60 (1998) 101-114.

17. N. Xu, J. Gong, Z. Huang, Review on the production methods and fundamental combustion characteristics of furan derivatives. Renew. Sustain. Energy Rev., 54 (2016) 1189-1211.

18. N.W. Tame, B.Z. Dlugogorski, E.M. Kennedy, Formation of dioxins and furans during combustion of treated wood. Prog. Energy Combust. Sci., 33 (2007) 384-408.

19. A.A. Meharg, K. Killham, A pre-industrial source of dioxins and furans. Nature, 421 (2003) 909-910.

20. M.A. Eldeeb, B. Akih-Kumgeh, Recent trends in the production, combustion and modeling of furan-based fuels. Energies, 11 (2018) 512.

21. L. Wei, C. Tang, X. Man, X. Jiang, Z. Huang, High-Temperature Ignition Delay Times and Kinetic Study of Furan. Energy \& Fuels, 26 (2012) 2075-2081.

22. Z. Tian, T. Yuan, R. Fournet, P.-A. Glaude, B. Sirjean, F. Battin-Leclerc, K. Zhang, F. Qi, An experimental and kinetic investigation of premixed furan/oxygen/argon flames. Combust. Flame, 158 (2011) 756-773.

23. D. Liu, C. Togbé, L.-S. Tran, D. Felsmann, P. Oßwald, P. Nau, J. Koppmann, A. Lackner, P.-A. Glaude, B. Sirjean, Combustion chemistry and flame structure of furan group biofuels using molecular-beam mass spectrometry and gas chromatography-Part I: Furan. Combust. Flame, 161 (2014) 748-765.

24. M. Sirignano, M. Conturso, A. D'Anna, Effect of furans on particle formation in diffusion flames: An experimental and modeling study. Proc. Combust. Inst., 35 (2015) 525-532.

25. Z. Cheng, Y. Tan, L. Wei, L. Xing, J. Yang, L. Zhang, Y. Guan, B. Yan, G. Chen, D.Y. Leung, Experimental and kinetic modeling studies of furan pyrolysis: Fuel decomposition and aromatic ring formation. Fuel, 206 (2017) 239-247.

26. L.-S. Tran, Z. Wang, H.-H. Carstensen, C. Hemken, F. Battin-Leclerc, K. KohseHöinghaus, Comparative experimental and modeling study of the low-to moderate- 
temperature oxidation chemistry of 2, 5-dimethylfuran, 2-methylfuran, and furan. Combust. Flame, 181 (2017) 251-269.

27. M.M. Thorton, P.C. Malte, A.L. Crittenden, Oxidation of furan and furfural in a wellstirred reactor. Symp. (Int.) Combust., 21 (1988) 979-989.

28. H. Wang, X. You, A.V. Joshi, S.G. Davis, A. Laskin, F. Egolfopoulos, C. Law, USC Mech Version II. High-temperature combustion reaction model of $\mathrm{H}_{2} / \mathrm{CO} / \mathrm{C}_{1}-\mathrm{C}_{4}$ compounds. Combustion Kinetics Laboratory, University of Southern California, Los Angeles, CA, accessed Aug 21 (2007) 2017.

29. C.-W. Zhou, Y. Li, U. Burke, C. Banyon, K.P. Somers, S. Ding, S. Khan, J.W. Hargis, T. Sikes, O. Mathieu, E.L. Petersen, M. AlAbbad, A. Farooq, Y. Pan, Y. Zhang, Z. Huang, J. Lopez, Z. Loparo, S.S. Vasu, H.J. Curran, An experimental and chemical kinetic modeling study of 1,3-butadiene combustion: Ignition delay time and laminar flame speed measurements. Combust. Flame, 197 (2018) 423-438.

30. A. Lifshitz, M. Bidani, S. Bidani, Thermal reactions of cyclic ethers at high temperatures. III. Pyrolysis of furan behind reflected shocks. J. Phys. Chem., 90 (1986) 5373-5377.

31. B. Chen, B.D. Ilies, W. Chen, Q. Xu, Y. Li, L. Xing, J. Yang, L. Wei, N. Hansen, H. Pitsch, S.M. Sarathy, Z. Wang, Exploring low temperature oxidation of 1-butene in jet-stirred reactors. Combust. Flame, 222 (2020) 259-271.

32. R.D. Johnson III, NIST Computational Chemistry Comparison and Benchmark Database, NIST Standard Reference Database Number 101, Release 16a http://cccbdb.nist. gov/(accessed Mar 13, 2015). 2013.

33. L.A. Curtiss, K. Raghavachari, Gaussian-3 and related methods for accurate thermochemistry. Theor. Chem. Acc., 108 (2002) 61-70.

34. X. He, L. Fusti-Molnar, K.M. Merz Jr, Accurate benchmark calculations on the gas-phase basicities of small molecules. J. Phys. Chem. A, 113 (2009) 10096-10103.

35. J.M. Martin, Ab initio total atomization energies of small molecules - towards the basis set limit. Chem. Phys. Lett., 259 (1996) 669-678.

36. R. Martin, K. Morokuma, V. Zakrzewski, G. Voth, P. Salvador, J. Dannenberg, S. Dapprich, A. Daniels, O. Farkas, J. Foresman, Gaussian 09, Revision D. 01. 2013: Wallingford CT.

37. P. Liu, Y. Zhang, Z. Li, A. Bennett, H. Lin, S.M. Sarathy, W.L. Roberts, Computational study of polycyclic aromatic hydrocarbons growth by vinylacetylene addition. Combust. Flame, 202 (2019) 276-291.

38. X. You, D.Y. Zubarev, W.A. Lester Jr, M. Frenklach, Thermal decomposition of pentacene oxyradicals. J. Phys. Chem. A, 115 (2011) 14184-14190.

39. P. Liu, H. Lin, Y. Yang, C. Shao, C. Gu, Z. Huang, New Insights into Thermal Decomposition of Polycyclic Aromatic Hydrocarbon Oxyradicals. J. Phys. Chem. A, 118 (2014) 11337-11345.

40. Y. Li, C.-W. Zhou, K.P. Somers, K. Zhang, H.J. Curran, The oxidation of 2-butene: A high pressure ignition delay, kinetic modeling study and reactivity comparison with isobutene and 1-butene. Proc. Combust. Inst., 36 (2017) 403-411.

41. G. da Silva, J.W. Bozzelli, Kinetic modeling of the benzyl $+\mathrm{HO}_{2}$ reaction. Proc. Combust. Inst., 32 (2009) 287-294.

42. J.R. Barker, Multiple-Well, multiple-path unimolecular reaction systems. I. MultiWell computer program suite. Int. J. Chem. Kinet., 33 (2001) 232-245. 
43. J. Zádor, A.W. Jasper, J.A. Miller, The reaction between propene and hydroxyl. Phys. Chem. Chem. Phys., 11 (2009) 11040-11053.

44. P. Liu, Y. Li, S.M. Sarathy, W.L. Roberts, Gas-to-Liquid Phase Transition of PAH at Flame Temperatures. J. Phys. Chem. A, 124 (2020) 3896-3903.

45. T. Tao, W. Sun, N. Hansen, A.W. Jasper, K. Moshammer, B. Chen, Z. Wang, C. Huang, P. Dagaut, B. Yang, Exploring the negative temperature coefficient behavior of acetaldehyde based on detailed intermediate measurements in a jet-stirred reactor. Combust. Flame, 192 (2018) 120-129.

46. Z. Wang, D.M. Popolan-Vaida, B. Chen, K. Moshammer, S.Y. Mohamed, H. Wang, S. Sioud, M.A. Raji, K. Kohse-Höinghaus, N. Hansen, Unraveling the structure and chemical mechanisms of highly oxygenated intermediates in oxidation of organic compounds. Proc. Nat. Acad. Sci., 114 (2017) 13102-13107.

47. K. Moshammer, A.W. Jasper, D.M. Popolan-Vaida, A. Lucassen, P. Diévart, H. Selim, A.J. Eskola, C.A. Taatjes, S.R. Leone, S.M. Sarathy, Detection and identification of the ketohydroperoxide (HOOCH2OCHO) and other intermediates during low-temperature oxidation of dimethyl ether. J. Phys. Chem. A, 119 (2015) 7361-7374.

48. E. Lemmon, M. McLinden, D. Friend, P. Linstrom, W. Mallard, NIST chemistry WebBook, Nist standard reference database number 69, National Institute of Standards and Technology 2011: Gaithersburg.

49. S. Dong, K. Zhang, P.K. Senecal, G. Kukkadapu, S.W. Wagnon, S. Barrett, N. Lokachari, S. Panigaphy, W.J. Pitz, H.J. Curran, A comparative reactivity study of 1-alkene fuels from ethylene to 1-heptene. Proc. Combust. Inst., (2020)

50. R. Kee, F. Rupley, J. Miller, M. Coltrin, J. Grcar, E. Meeks, H. Moffat, A. Lutz, G. DixonLewis, M. Smooke, Chemkin-Pro, ANSYS reaction design. 2008: San Diego, CA.

51. C.F. Goldsmith, W.H. Green, S.J. Klippenstein, Role of $\mathrm{O}_{2}+$ QOOH in low-temperature ignition of propane. 1. Temperature and pressure dependent rate coefficients. J. Phys. Chem. A, 116 (2012) 3325-3346.

52. S.M. Sarathy, S. Vranckx, K. Yasunaga, M. Mehl, P. Oßwald, W.K. Metcalfe, C.K. Westbrook, W.J. Pitz, K. Kohse-Höinghaus, R.X. Fernandes, H.J. Curran, A comprehensive chemical kinetic combustion model for the four butanol isomers. Combust. Flame, 159 (2012) 2028-2055.

53. P. Liu, H. Lin, Y. Yang, C. Shao, B. Guan, Z. Huang, Investigating the Role of $\mathrm{CH}_{2}$ Radicals in the HACA Mechanism. J. Phys. Chem. A, 119 (2015) 3261-3268.

54. P. Liu, H. Jin, B. Chen, J. Yang, Z. Li, A. Bennett, A. Farooq, S. Mani Sarathy, W.L. Roberts, Rapid soot inception via $\alpha$-alkynyl substitution of polycyclic aromatic hydrocarbons. Fuel, 295 (2021) 120580.

55. J. Bai, C. Cavallotti, C.-W. Zhou, Theoretical kinetics analysis for $\mathrm{OH}$ radical addition to 1, 3-butadiene and application to model prediction. Combust. Flame, 221 (2020) 228-240.

56. B. Chen, D.B. Ilies, N. Hansen, H. Pitsch, S.M. Sarathy, Simultaneous production of ketohydroperoxides from low temperature oxidation of a gasoline primary reference fuel mixture. Fuel, (2020) 119737.

57. B. Yang, J. Wang, T.A. Cool, N. Hansen, S. Skeen, D.L. Osborn, Absolute photoionization cross-sections of some combustion intermediates. Int. J. Mass Spectrom., 309 (2012) 118128.

58. D. Ray, R.R. Diaz, D. Waddington, Gas-phase oxidation of butene-2: The role of acetaldehyde in the reaction. Symp. (Int.) Combust., 14 (1973) 259-266. 
59. Y. Zhu, C.-W. Zhou, Chemical kinetics study of 1, 3-butadiene+ $\mathrm{HO}_{2}$; implications for combustion modeling and simulation. Combust. Flame, 221 (2020) 241-255.

60. A. Karton, Highly accurate ccsdt (q)/cbs reaction barrier heights for a diverse set of transition structures: basis set convergence and cost-effective approaches for estimating post-ccsd (t) contributions. J. Phys. Chem. A, 123 (2019) 6720-6732.
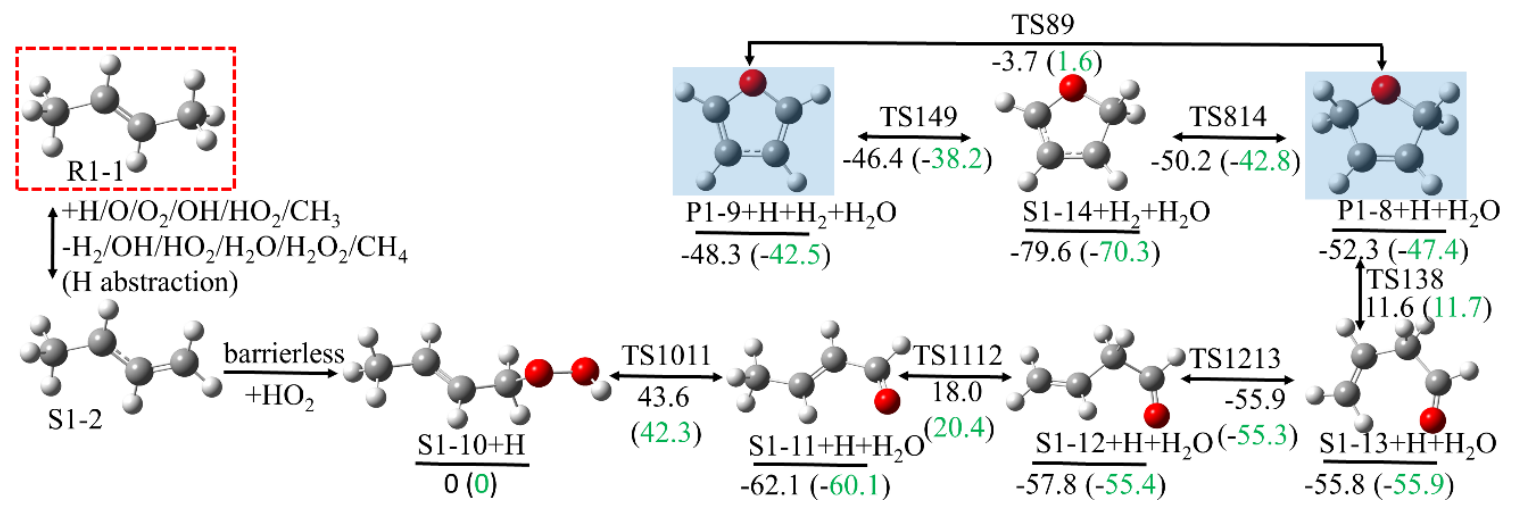

Figure 1: The furan formation from $\mathrm{H}$-atom abstraction of trans-2-butene (R1-1 reaction network), green values are from the G3 method and black values are from the CCSD(T)/cc-pvdz method.

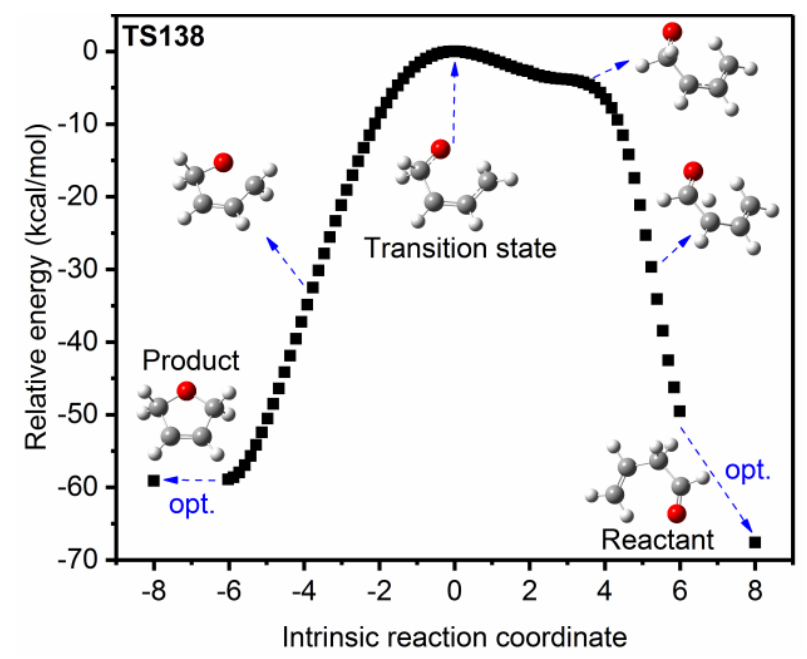

Figure 2: The MEP for TS138. 


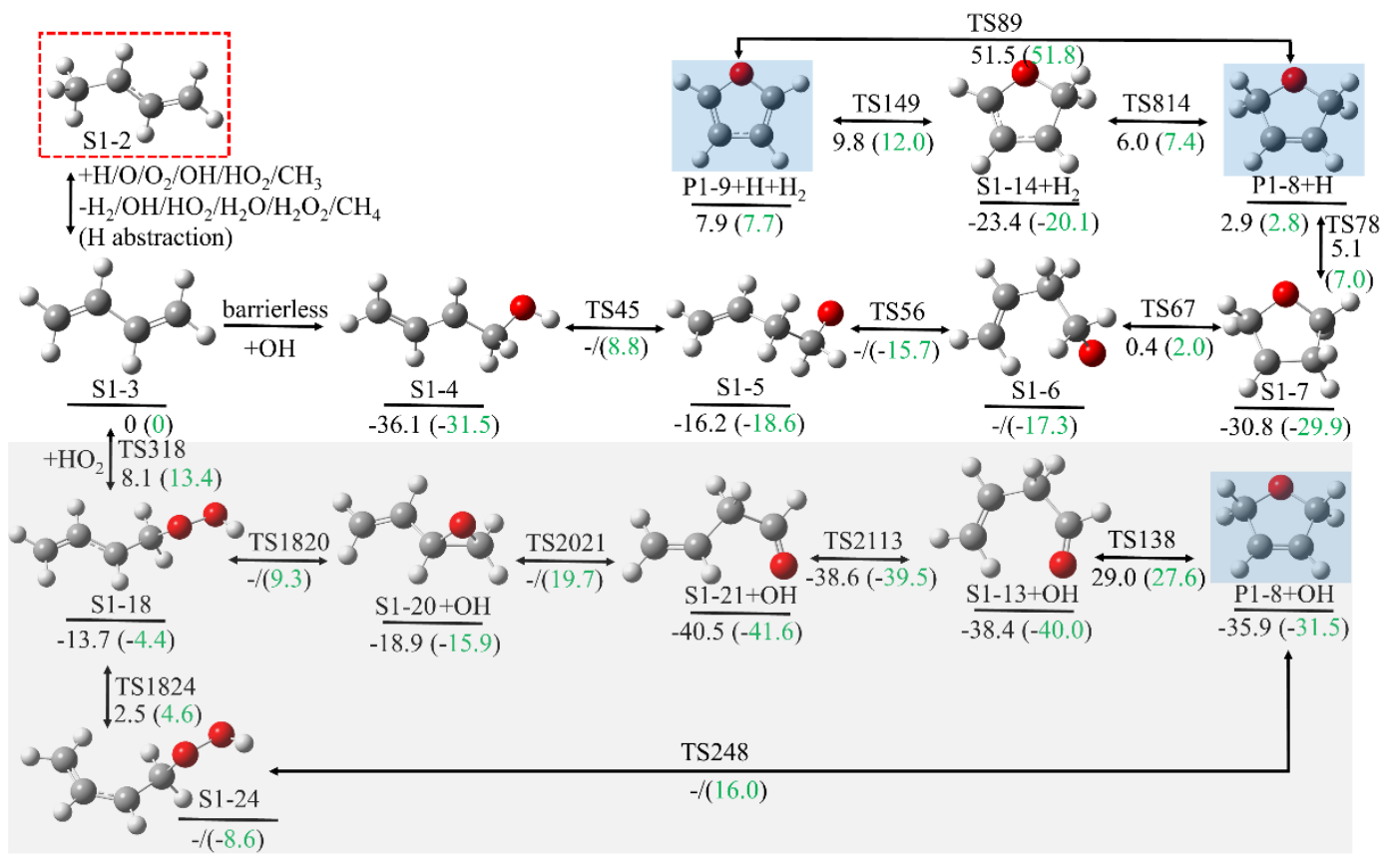

Figure 3: The furan formation from $\mathrm{H}$-atom abstraction of 2-butenyl (R1-1 reaction network), green values are from the G3 method and black values are from the CCSD(T)/cc-pvdz method.
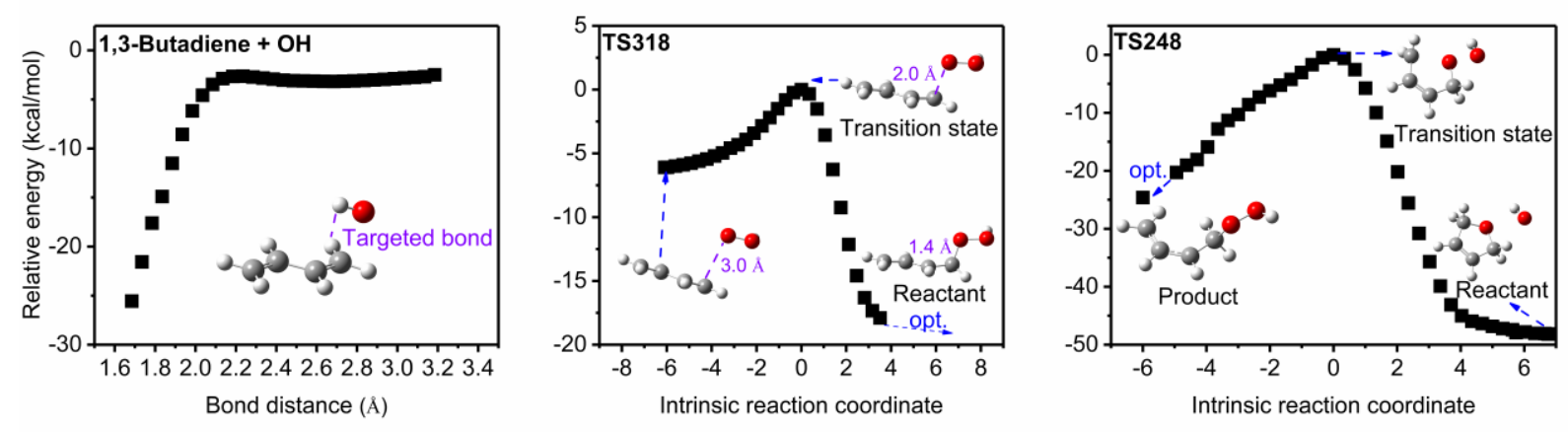

Figure 4: The MEP for (a) S1-3 + OH, (b) TS318, (c) TS248. 


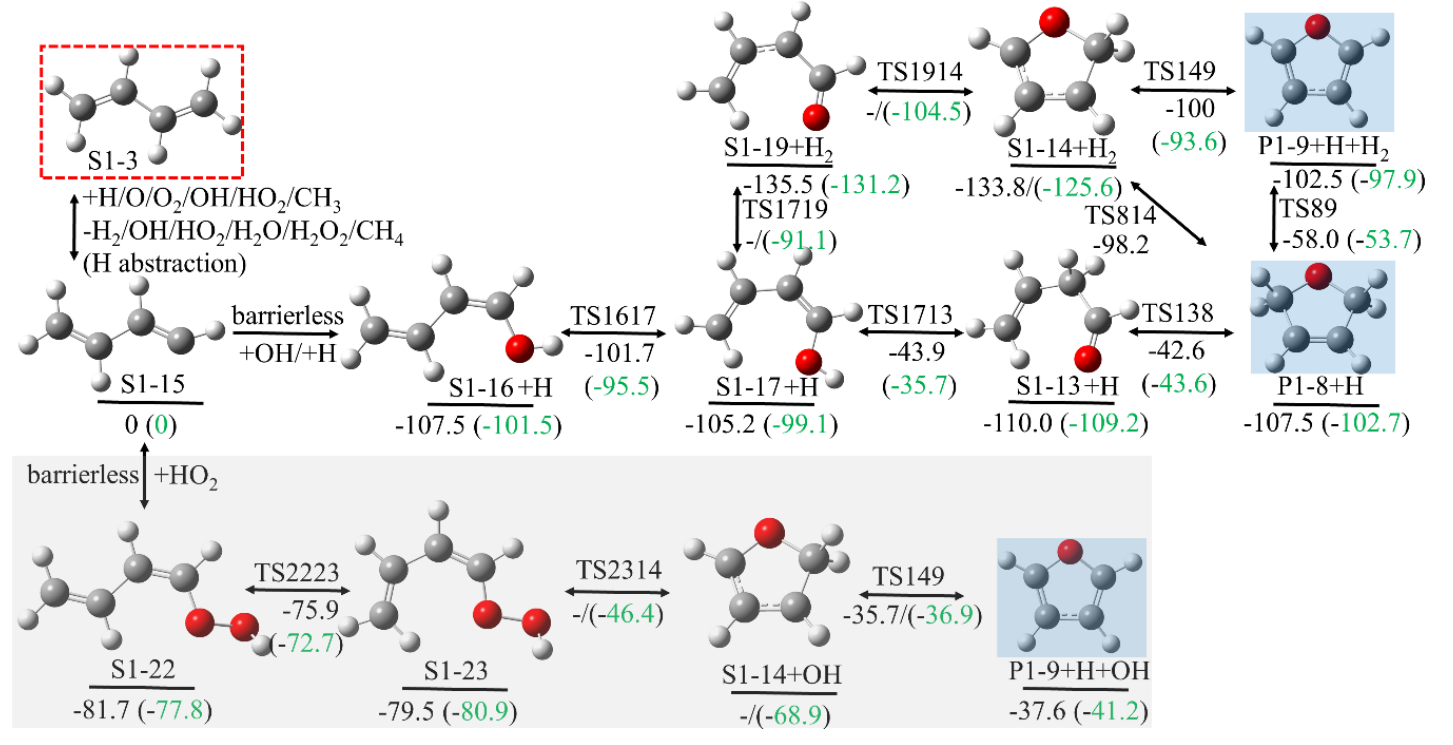

Figure 5: The furan formation from 1,3-butadiene (R1-1 reaction network) green values are from the G3 method and black values are from the CCSD(T)/cc-pvdz method.

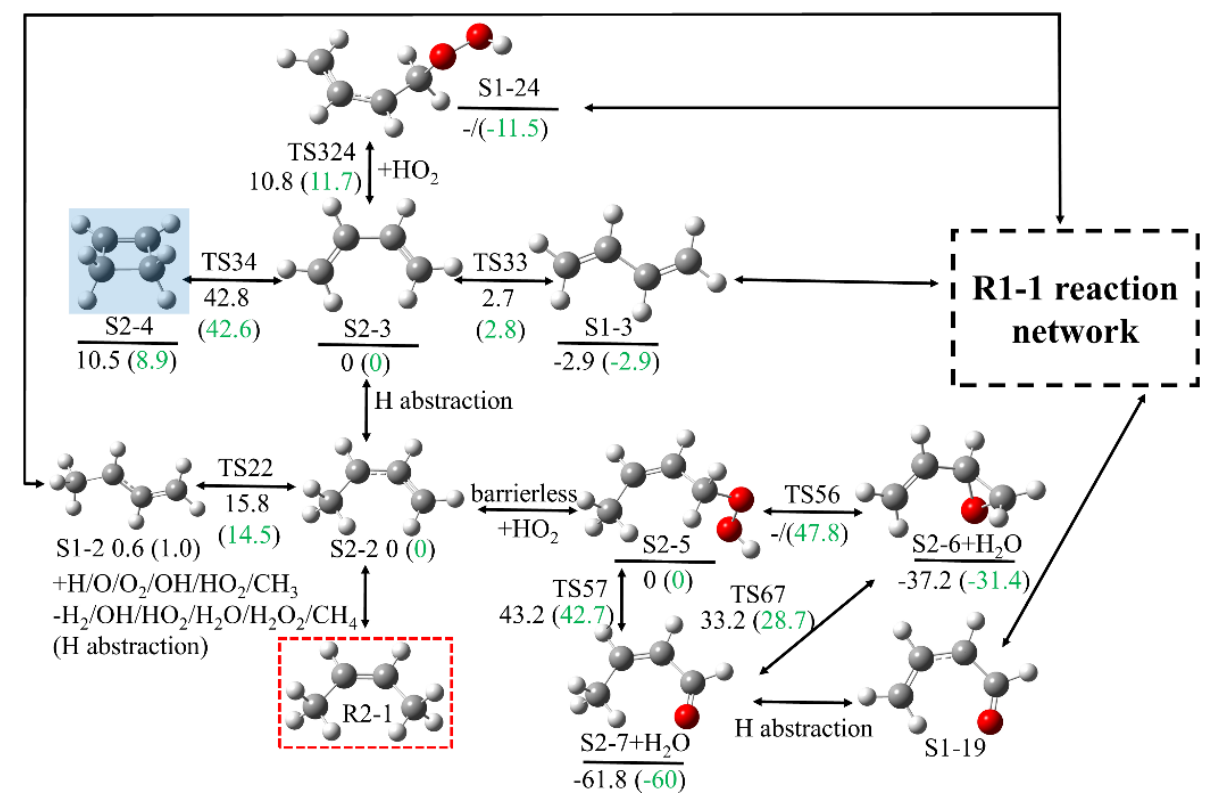

Figure 6: The furan formation pathway starting from cis-2- $\mathrm{C}_{4} \mathrm{H}_{8}(\mathrm{R} 2-1$ reaction network) green values are from the G3 method and black values are from the $\operatorname{CCSD}(\mathrm{T}) / \mathrm{cc}-\mathrm{pvdz}$ method. 


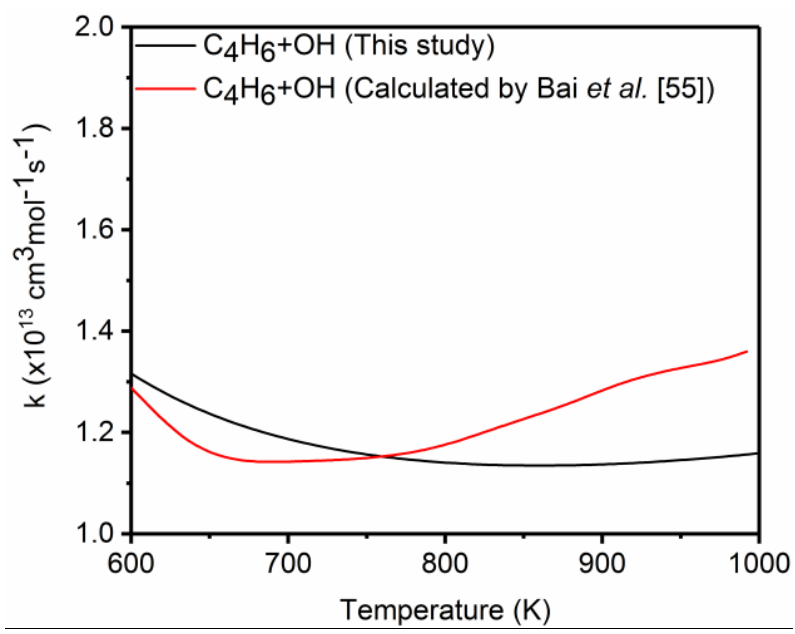

Figure 7: High pressure limits reaction rate coefficients of $\mathrm{C}_{4} \mathrm{H}_{6}+\mathrm{OH}$ addition reaction.

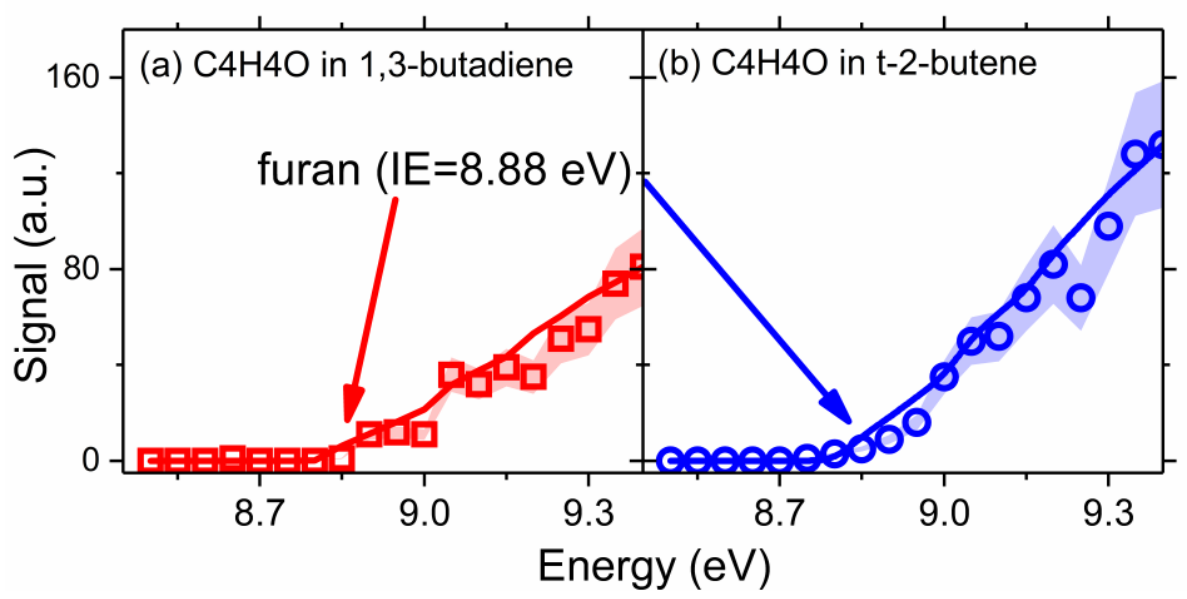

Figure 8: PIE curves of $\mathrm{C}_{4} \mathrm{H}_{4} \mathrm{O}$. JSR conditions: $1.0 \%$ fuel (left: 1,3-butadiene case; right: trans-2butene case), $\varphi=0.2, \tau=4 \mathrm{~s}, \mathrm{~T}=830 \mathrm{~K}$. Scattered points are measurements; lines are fits from cross sections in the database [57]; shaded areas indicate the experimental error. 


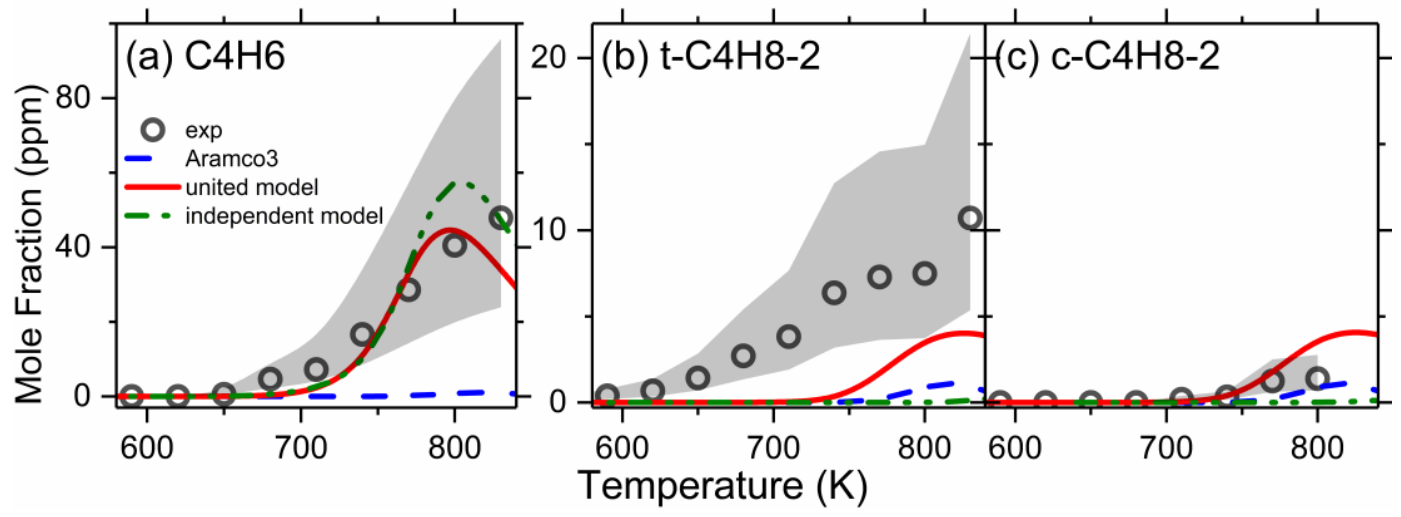

Figure 9: Temperature versus mole fraction profiles of furan by the experiments (open points) and numerical simulations using different kinetic models (lines) for (a) 1,3-butadiene case; (b) trans2-butene case; (c) cis-2-butene case. JSR conditions: $1.0 \%$ fuel, $\varphi=0.2, \tau=4 \mathrm{~s}, \mathrm{~T}=590-830 \mathrm{~K}$. The shaded area indicates the experimental error.

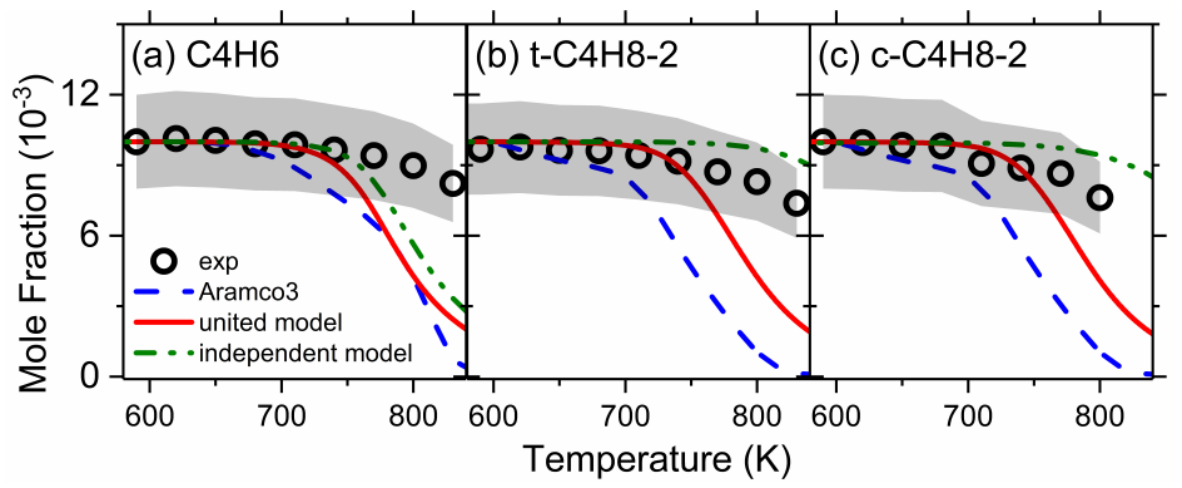

Figure 10: Temperature versus mole fraction profiles of the fuels by the experiments (open points) and numerical simulations using different kinetic models (lines). Left: 1,3-butadiene case; Middle: trans-2-butene case; Right: cis-2-butene case. JSR conditions: $1.0 \%$ fuel, $\varphi=0.2, \tau=4 \mathrm{~s}, \mathrm{~T}=590-830$ K. The shaded area indicates the experimental error. 


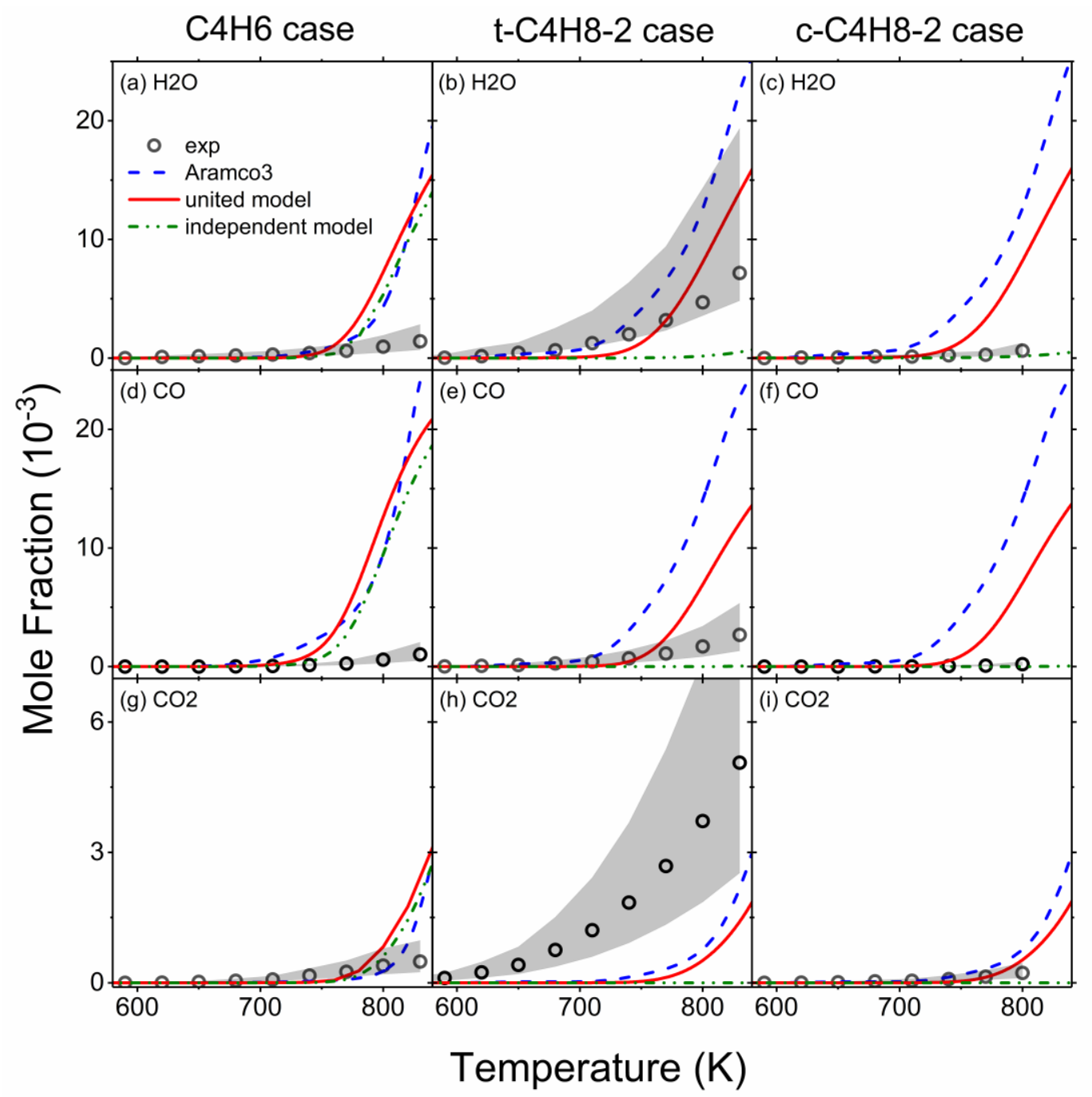

Figure 11: Temperature versus mole fraction profiles of the main products from the experiments (open points) and numerical simulations using different kinetic models (lines). Left: 1,3-butadiene case; Middle: trans-2-butene case; Right: cis-2-butene case. JSR conditions: $1.0 \%$ fuel, $\varphi=0.2, \tau=4$ s, $\mathrm{T}=590-830 \mathrm{~K}$. The shaded areas indicate the experimental error. 


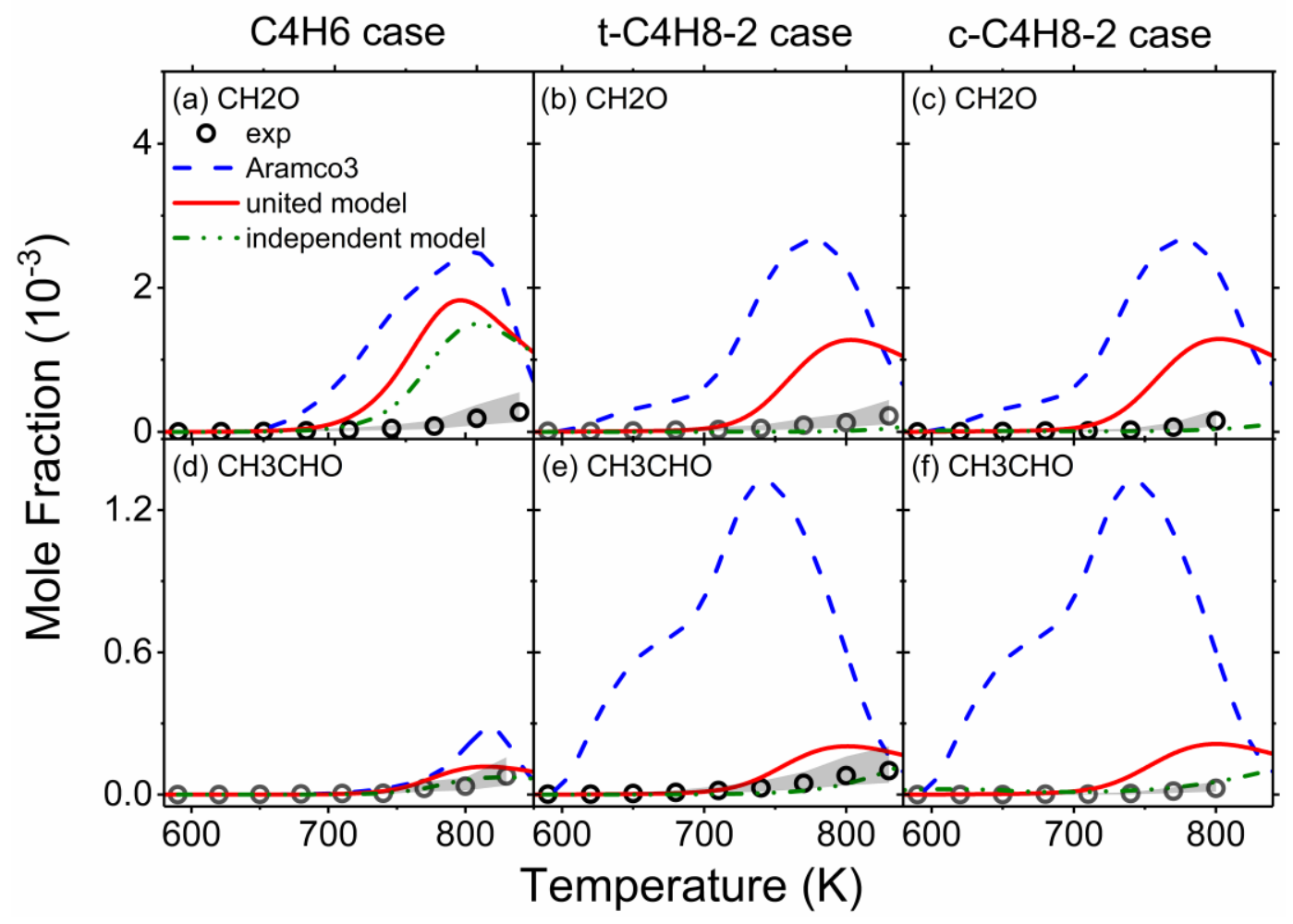

Figure 12: Temperature versus mole fraction profiles of the formaldehyde and acetaldehyde from the experiments (open points) and numerical simulations using different kinetic models (lines). Left: 1,3-butadiene case; Middle: trans-2-butene case; Right: cis-2-butene case. JSR conditions: $1.0 \%$ fuel, $\varphi=0.2, \tau=4 \mathrm{~s}, \mathrm{~T}=590-830 \mathrm{~K}$. The shaded areas indicate the experimental error. 


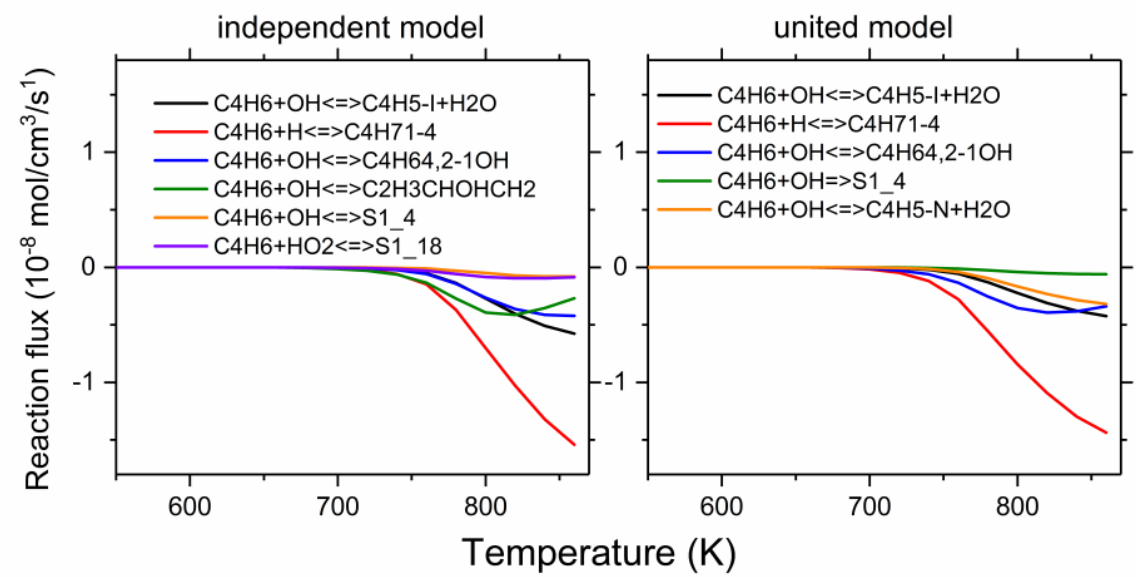

Figure 13: Rate of production analysis of fuel consumption in 1,3-butadiene case. Simulation conditions: $1.0 \%$ fuel, $\varphi=0.2, \tau=4 \mathrm{~s}, \mathrm{~T}=550-860 \mathrm{~K}$.

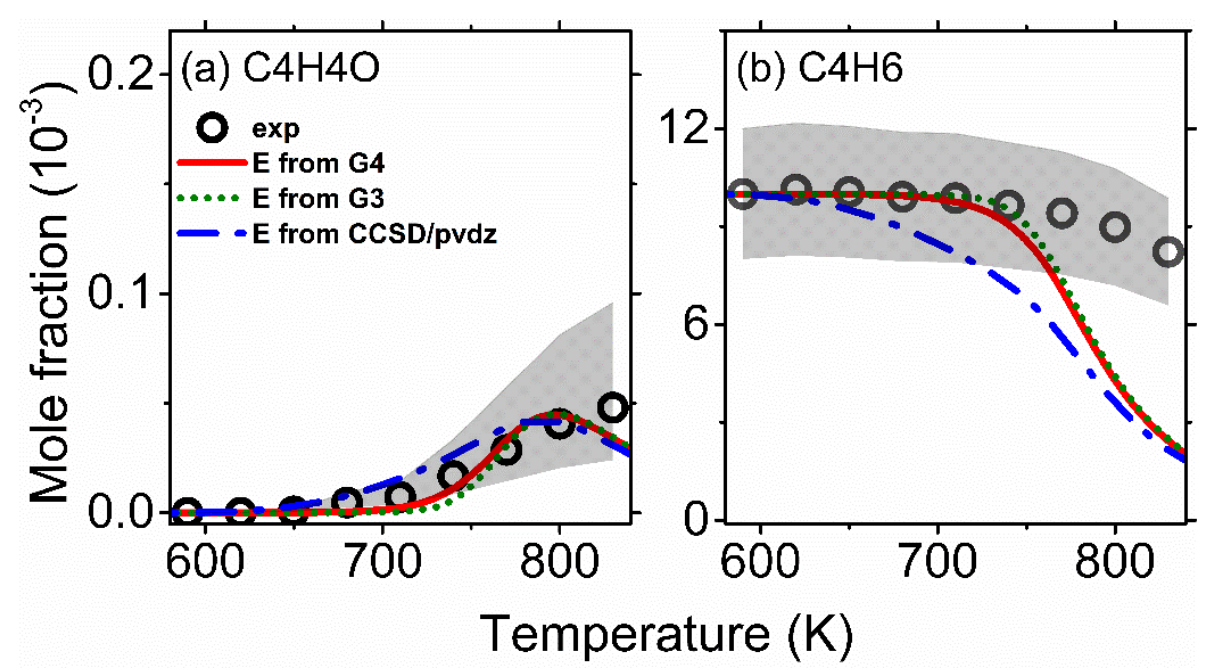

Figure 14: The temperature versus mole fraction profiles of furan by the experiments and numerical simulations using the variation of energy barrier from different quantum chemistry methods in reaction $\mathrm{C}_{4} \mathrm{H}_{6}+\mathrm{HO}_{2} \rightleftharpoons \mathrm{S} 1-18$ in the uniform model. JSR conditions: $1.0 \%$ of 1,3butadiene, $\varphi=0.2, \tau=4 \mathrm{~s}, \mathrm{~T}=550-860 \mathrm{~K}$. The shaded area indicates the experimental error. 

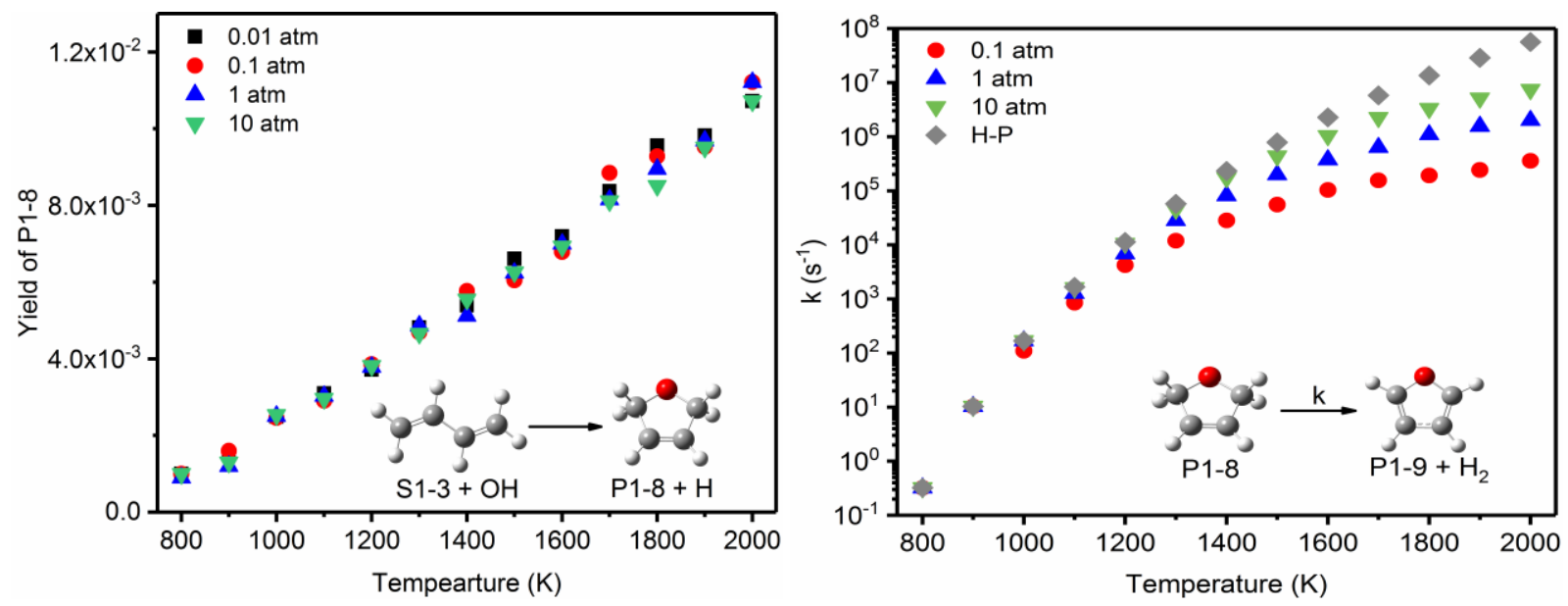

Figure 15: Pressure dependence for the main furan formation pathway by RRKM-ME calculation.

(a) The yield of P1-8 in S1-3+OH $\rightarrow \mathrm{S} 1-4 \rightarrow \mathrm{S} 1-5 \rightarrow \mathrm{S} 1-6 \rightarrow \mathrm{S} 1-7 \rightarrow \mathrm{P} 1-8+\mathrm{H}$ pathway. (b) The decomposition reaction rate coefficient of $\mathrm{P} 1-8 \rightarrow \mathrm{P} 1-9+\mathrm{H}_{2}$. 